Review

\title{
Current Status on Pulsed Laser Deposition of Coatings from Animal-Origin Calcium Phosphate Sources
}

\author{
Liviu Duta ${ }^{1, *(D)}$ and Andrei C. Popescu ${ }^{2, *}$ \\ 1 Lasers Department, National Institute for Lasers, Plasma, and Radiation Physics, 409 Atomistilor Street, \\ 077125 Magurele, Romania \\ 2 Center for Advanced Laser Technologies (CETAL), National Institute for Lasers, Plasma and Radiation \\ Physics, 077125 Magurele, Romania \\ * Correspondence: liviu.duta@inflpr.ro (L.D.); andrei.popescu@inflpr.ro (A.C.P.)
}

Received: 30 April 2019; Accepted: 22 May 2019; Published: 24 May 2019

check for updates

\begin{abstract}
The aim of this paper is to present the current status on animal-origin hydroxyapatite (HA) coatings synthesized by Pulsed Laser Deposition (PLD) technique for medical implant applications. PLD as a thin film synthesis method, although limited in terms of surface covered area, still gathers interest among researchers due to its advantages such as stoichiometric transfer, thickness control, film adherence, and relatively simple experimental set-up. While animal-origin HA synthesized by bacteria or extracted from animal bones, eggshells, and clams was tested in the form of thin films or scaffolds as a bioactive agent before, the reported results on PLD coatings from HA materials extracted from natural sources were not gathered and compared until the present study. Since natural apatite contains trace elements and new functional groups, such as $\mathrm{CO}_{3}{ }^{2-}$ and $\mathrm{HPO}_{4}{ }^{2-}$ in its complex molecules, physical-chemical results on the transfer of animal-origin HA by PLD are extremely interesting due to the stoichiometric transfer possibilities of this technique. The points of interest of this paper are the origin of HA from various sustainable resources, the extraction methods employed, the supplemental functional groups, and ions present in animal-origin HA targets and coatings as compared to synthetic HA, the coatings' morphology function of the type of HA, and the structure and crystalline status after deposition (where properties were superior to synthetic HA), and the influence of various dopants on these properties. The most interesting studies published in the last decade in scientific literature were compared and morphological, elemental, structural, and mechanical data were compiled and interpreted. The biological response of different types of animal-origin apatites on a variety of cell types was qualitatively assessed by comparing MTS assay data of various studies, where the testing conditions were possible. Antibacterial and antifungal activity of some doped animal-origin HA coatings was also discussed.
\end{abstract}

Keywords: animal-origin calcium phosphate coatings; natural hydroxyapatite; doping; high adherence; pulsed laser deposition technique; biomimetic applications

\section{Introduction}

In the last few decades, the field of bone tissue engineering has been widely studied and expanded for addressing bone-related traumas. By combining biomaterials and cells for bone tissue ingrowth, an efficient and viable alternative to allografts or autografts could be delivered.

Bioactive materials represent a vast bioengineering research field with tremendous interest for the production of durable implants and bone substitutes able to bypass rejection difficulties.

Calcium phosphates $(\mathrm{CaP})$ are bio-ceramic materials used especially for orthopedic and dental medical applications [1,2]. Synthetic hydroxyapatite (HA), with the complex chemical formula 
$\mathrm{Ca}_{10}\left(\mathrm{PO}_{4}\right)_{6}(\mathrm{OH})_{2}$, is the most well-known CaP material, and is frequently used in implantology due to its close chemical composition and crystallographic structure resemblance with the mineral phase of vertebrate bones (50\% in mass and 70\% in volume) [3-5]. We stress upon that the mineral constituent of vertebrate skeletal systems mainly consists of a calcium-deficient HA, doped with various ions [6]. According to the biomimetic approach, a material designed to repair the skeletal system must be similar to the biological one in terms of composition, stoichiometry, the crystallinity degree, morphology, and functionality. It was reported that HA can promote new bone in-growth through the osteoconduction mechanism without eliciting local or systemic toxicity, inflammation, or foreign body response [7-9]. When an HA-based ceramic is implanted, a fibrous tissue-free layer containing carbonated apatite forms on its surfaces and contributes to the implant bonding to the bone. This results in earlier implant stabilization and superior fixation of the implant to the surrounding tissues [8-10]. Moreover, the development of microbial biofilms onto the surface of medical devices or human tissues represents a worrying health problem, which can lead to a high diversity of biofilm-associated infections, with increasing incidence [11]. Therefore, the antimicrobial properties of HA are also of key importance $[12,13]$. Taking into account all these demands, one could, therefore, explain the large interest for synthesis and deposition of apatites enriched with biologically-active ions or molecules, as well as more resorbable (soluble) CaPs.

Despite its excellent bone regeneration properties, HA has also some important disadvantages: HA-based ceramics are very brittle in bulk [14] and are characterized by poor mechanical properties, especially in liquid media. Therefore, HA-based materials cannot be used in bulk for orthopedic devices, which must withstand the application of high loads during their lifetime [15]. To overcome these drawbacks, HA can be applied as a coating onto the surface of metallic or polymeric implants, which aim to significantly improve implants' overall performances, by successfully combining the excellent bioactivity of the ceramic with the mechanical advantages of the substrate implants $[14,16]$.

Various techniques have been and are continuously developed to obtain HA. In this respect, they can be categorized in two main paths of producing HA: (i) the first one implies the use of chemical routes, and (ii) the second one involves extracting it naturally, from biogenic, mammalian, or fish bone sustainable, low-cost resources (further denoted as BioHA).

For depositing CaP coatings onto metallic implants, the industrial technique of choice is plasma-spraying, due to the synthesis speed, large area of deposition, and work in an ambient atmosphere [17]. However, HA coatings produced using this technique are prone to cracking and delamination and, because of high-processing temperatures, could contain residual decomposition phases. In this respect, current interests are quickly advancing toward two focused research directions: (i) increasing the biomimicry of HA-based coatings with respect to the composition and structure of bone apatite, and (ii) improving or even discovering alternative deposition techniques, which can allow for the achievement of novel HA (doped) coatings with increased mechanical and biological characteristics.

When compared to other physical vapor deposition techniques, i.e. thermal evaporation or sputtering, the pulsed laser deposition (PLD) technique stands as a simple, versatile, rapid, and cost-effective method, which can enable precise control of thickness and morphology for the fabrication of high-quality films $[18,19]$. The main advantage of the PLD technique applied for HA-based bio-ceramics is represented by its capacity to grow stoichiometric films with a controlled degree of crystallinity and thickness. By this method, one can assure the flexibility to control the morphology, phase, crystallinity, and chemical composition of obtained CaPs. These characteristics have a special influence over bio-resorption or dissolution, which are directly involved in the process of films' osseointegration.

Taking into account all these aspects, the aim of the current review is to emphasize the advantages of using animal-origin HA coatings as viable substitutes of synthetic HA ones, which are fabricated by the PLD technique for implantable applications. Conclusions will be drawn, future perspectives will be advanced, and a series of recommendations will be highlighted. 


\section{Review of Literature}

A digital search was performed using Web of Science (http://apps.webofknowledge.com), following the criteria described below.

\subsection{Inclusion Criteria}

1. Articles written in English. 2. Use of animal-origin HA materials for physical-chemical, in vitro and in vivo studies. 3. Pulsed laser deposition as the technique used for the synthesis of animal-origin HA coatings. 4. Articles written starting from the year 2001.

\subsection{Exclusion Criteria}

1. Non-English articles. 2. Nanoparticles. 3. Other deposition techniques (such as Plasma spraying, Magnetron sputtering, etc.) used for the synthesis of animal-origin HA coatings.

After the review process, a total of 49 articles met the inclusion criteria and were further assessed in detail and parts of the reported results were considered and discussed in this review.

\section{BioHA vs. Synthetic HA}

Various methods have been used to obtain HA due to its attractive biological properties and resemblance to the mineral part of the bone. There are two main categories of methods used to produce HA.

(i) The first one, which is generally utilized due its reliability, implies the use of inorganic synthesis by different methods, such as hydrothermal [20,21], co-precipitation [22,23], or sol-gel [24]. However, these approaches are, on one hand, polluting and time-consuming, and, on the other hand, quite expensive $[25,26]$. Moreover, the resulting synthetic HA, which is a stoichiometric material with $\mathrm{Ca} / \mathrm{P}$ ratio of 1.67 , does not completely match the chemical composition of bone [27].

(ii) Thus, researchers managed to find alternative, low-cost methods to produce HA, such as obtaining it from biogenic, mammalian, or natural fish bone (sustainable/renewable) sources. BioHA is a carbonated, non-stoichiometric Ca-deficient material with a reduced degree of crystallinity. Therefore, it differs from synthetic HA in terms of composition, stoichiometry, crystal size/morphology, crystallinity degree, degradation rate, and overall biological performance. One should also note that there might exist some concerns about the use of natural HA because of the potential risk of dangerous diseases transmission, when the material is not well-prepared [27]. However, when all health security issues are handled [28,29], then HA derived directly from sustainable, low production cost materials (such as animal bones) has a composition that closely matches the morphological and structural architecture of the inorganic components of the human bone. In fact, it has been reported that HA obtained from biowaste such as eggshells, bovine bones, fish-scales, and fish bones can lead to overall properties and behavior comparable or even better than synthetic ones due to the similarities of bone apatites $[2,30,31]$. However, in order to completely benefit from the previously mentioned advantages against synthetic HA, BioHA should be extracted in a controlled manner, i.e., from resources for which one knows the exact alimentation and way of life of animals, since this could directly influence the overall quality of the final product, $\mathrm{HA}$.

Functional groups from biological apatites can be substituted with trace amounts of cations $\left(\mathrm{Na}^{+}, \mathrm{Mg}^{2+}\right.$, and $\left.\mathrm{K}^{+}\right)$, anions $\left(\mathrm{F}^{-}, \mathrm{Cl}^{-}, \mathrm{SiO}_{4}{ }^{4-}\right.$ and $\left.\mathrm{CO}_{3}{ }^{2-}\right)$, or, in some cases, by both $[2,32,33]$, either adsorbed on the surface of the crystal or incorporated in the lattice structure [34-37]. Specifically, in the apatite structure, the carbonate ions can replace either the hydroxyl or the phosphate ion sites, which leads to a type-A or type-B structure [38]. If these substitutions take place simultaneously, a type- $\mathrm{AB}$ substitution occurs, as in the case of the bone mineral $[32,39,40]$. One should note that the mineral bone substitutions with various trace elements are considered directly responsible for the modifications in crystallinity, solubility, and biological response [41] and, therefore, they play a key role in the performance of hard tissues and the overall osseointegration process. As a consequence, 
alternative methods used to modify the HA structure by incorporating different ions to improve the osteoconductive properties of synthetic HA is currently of interest to the scientific community [2].

Apatite crystals produced in the biological system are different in many ways from the crystals obtained using synthetic precursors. The apatite crystals grown in the living system bear smaller crystallite size. Therefore, they have a large surface area, which further allows them to absorb an extra number of ions. In short, biological minerals tend to attain an organized structure in a very short time [42].

Table 1 introduces the sample codes, which will be further used in the text.

Table 1. Sample acronyms related to different materials used throughout the review and their explanation.

\begin{tabular}{cl}
\hline Sample Code & \multicolumn{1}{c}{ Sample Description } \\
\hline $\mathrm{Ti}$ & Titanium (control specimen or deposition substrate) \\
$\mathrm{HA}_{\text {syn }}$ & Synthetic hydroxyapatite \\
$\mathrm{DHA}$ & Dentine hydroxyapatite \\
BHA & Bovine hydroxyapatite \\
SHA & Ovine (sheep) hydroxyapatite \\
BHA:Li & Bovine hydroxyapatite doped with $\mathrm{Li}_{2} \mathrm{O}$ \\
BHA:CIG & Bovine hydroxyapatite doped with commercial inert glass \\
SHA:Ti & Ovine (sheep) hydroxyapatite doped with titanium \\
BHA:MgF & Bovine hydroxyapatite doped with $\mathrm{MgF}_{2}$ \\
BHA:MgO & Bovine hydroxyapatite doped with $\mathrm{MgO}^{\mathrm{M}}$ \\
BHA: $\mathrm{LiC}$ & Bovine hydroxyapatite doped with $\mathrm{Li}_{2} \mathrm{CO}_{3}$ \\
BHA: $\mathrm{LiP}$ & Bovine hydroxyapatite doped with $\mathrm{Li}_{3} \mathrm{PO}_{4}$ \\
\hline
\end{tabular}

The use of BioHA comes from the ambition and continuous efforts of researchers to attain biomimetism. While the chemically-synthesized HA is similar to the mineral part of the bone, it lacks trace elements and functional groups that modify the chemical formula of the natural HA in bone. Because of the fact that it is too laborious and probably impossible to chemically synthesize HA with the right amounts of trace elements and functional groups, an easy method is to isolate the biological HA from bones of various animals, to transform it into powder, and to press it into pellets that will be further used as PLD targets. Mammalian bones contain a higher source of ions and trace elements [43-46], with $\mathrm{Mg}^{2+}$ and $\mathrm{Na}^{+}$being the most frequently found ones. One notes that the presence of $\mathrm{Na}^{+}$and $\mathrm{Mg}^{2+}$ ions alongside HA play an important role in the development of teeth and bone, whereas their absence could cause bone loss and fragility [2]. Other trace elements such as $\mathrm{K}^{+}$, $\mathrm{Sr}^{2+}, \mathrm{Zn}^{2+}, \mathrm{Si}^{4+}, \mathrm{Ba}^{2+}, \mathrm{F}^{-}$, and $\mathrm{Al}^{-}$have been identified. However, the overall concentration of these elements can vary and this is due to differences in the diet of the animals [47].

BioHA mainly differentiates from chemically synthesized HA by the presence of carbonate ions. The $\mathrm{Ca}_{10}\left(\mathrm{PO}_{4}\right)_{6}(\mathrm{OH})_{2}$ complex formula of pure HA changes into:

$$
\mathrm{Ca}_{10-\mathrm{x}}\left(\mathrm{PO}_{4}\right)_{6-\mathrm{x}}\left(\mathrm{CO}_{3}\right)_{\mathrm{x}}(\mathrm{OH})_{2-\mathrm{x}}
$$

where $0 \leq \mathrm{x} \leq 2$ [48].

Another possibility can be that in $\left(\mathrm{PO}_{4}\right)^{3-}$ sites to find hydrogen phosphate $\left(\mathrm{HPO}_{4}\right)^{2-}$ ions [49]. Winand et al. [50] proposed a general formula for hydrogen phosphate-containing apatites:

$$
\mathrm{Ca}_{10-\mathrm{x}}\left(\mathrm{PO}_{4}\right)_{6-\mathrm{x}}\left(\mathrm{HPO}_{4}\right)_{\mathrm{x}}(\mathrm{OH})_{2-\mathrm{x}}
$$

where $0 \leq x \leq 2$. 
However, it is highly possible that BioHA can concomitantly have substitutions with $\mathrm{CO}_{3}{ }^{2-}$ and $\mathrm{HPO}_{4}{ }^{2-}$ groups. Hence, Combes et al. [37] advanced the following formula:

$$
\mathrm{Ca}_{10-\mathrm{x}}\left(\mathrm{PO}_{4}\right)_{6-\mathrm{x}}\left(\mathrm{CO}_{3} \text { or } \mathrm{HPO}_{4}\right)_{x}\left(\mathrm{OH} \text { or } 1 / 2 \mathrm{CO}_{3}\right)^{2-x}
$$

where $0 \leq x \leq 2$.

It should be mentioned that various studies showed a deviation of $\mathrm{OH}^{-}$groups in the composition of bone-extracted apatites as compared to the standard HA formula. A possible explanation could be that $\mathrm{PO}_{4}{ }^{3-}$ groups are reactive with water molecules trapped in the lattice or from the surrounding medium, which results in the formation of hydrogen phosphate:

$$
\mathrm{H}_{2} \mathrm{O}+\mathrm{PO}_{4}{ }^{3-} \rightarrow \mathrm{HPO}_{4}{ }^{2-}+\mathrm{OH}^{-} .
$$

Trace elements in the composition of BioHA materials are commonly determined qualitatively by spectroscopic techniques. It should be noted that there are chemical methods that involve dissolution of the mineral part of the bone and identification of constituents, but they are susceptible to post-decomposition chemical reactions. For metallic ions such as $\mathrm{Na}, \mathrm{K}, \mathrm{Al}$, and $\mathrm{Sr}$, it is believed that they do not influence the apatite properties, as long as they remain in the normal concentrations known for the human body. However, by accumulation following diet intake, some elements' increased content might cause biological reactions such as bone weakening or induction of osteoporosis.

A trace element with a clear effect on bones is fluorine, which forms in bone apatites fluoride ions. In addition, $99 \%$ of fluorine in most organisms is accumulated in bones in the form of fluorides (as e.g. NaF) [51]. In the human body, the fluorine content is of $0.05 \%$ to $0.1 \%$. Its presence favorizes an increase of bone density, but, in high content, causes a disease called fluorosis, in which bones become hard and brittle. Studies suggest that fluoride also has anti-plaque properties. It was reported that amine fluoride and stannous fluoride possess bactericidal properties against oral bacteria [52].

Dopants may have an important role in the structure and properties of BioHA coatings. For the crystallites size function of dopant materials in the case of BioHA coatings synthesized by PLD, the reader is guided to consult Table 2. Duta et al. [25] observed that a percentage of $1.5 \mathrm{wt} . \% \mathrm{Ti}$ in composition of PLD targets from SHA causes synthesis of layers with a reduced degree of crystallinity. Deposited SHA coatings without Ti display a crystallinity degree of $\sim 30 \%$, while, for the ones doped with $\mathrm{Ti}$, deposited in the same experimental conditions, the crystallinity degree dropped to $7 \%$ only.

Table 2. Crystalline coherence length in the case of BioHA coatings synthesized by PLD, function of doping materials. Determinations were performed along the $c$-axis [(002) crystal plane] and $a$-axis [(300) crystal plane] by applying the Scherrer Equation.

\begin{tabular}{ccccc}
\hline Sample Material & D002 (nm) & D300 (nm) & D002/D300 & Reference \\
\hline HA $_{\text {syn }}$ & 59.2 & 47.4 & 1.25 & {$[53]$} \\
\hline SHA & 50.1 & 48.5 & 1.03 & {$[25]$} \\
\hline BHA & 152.8 & 103.8 & $\sim 1.47$ & {$[54]$} \\
\hline SHA:Ti & 41.6 & 32.1 & 1.30 & {$[25]$} \\
\hline BHA:Li & 83.5 & 56 & 1.49 & {$[53]$} \\
BHA:CIG & 48.9 & 23.4 & 2.1 & \\
\hline BHA:MgF & 100.0 & 89.6 & $\sim 1.11$ & {$[54]$} \\
BHA:MgO & 169.7 & 141.2 & $\sim 1.20$ & \\
\hline
\end{tabular}

BHA was doped with various elements in order to identify their role on the crystallinity of the obtained coatings. Thus, it was shown that by inserting $1 \mathrm{wt} . \%$ lithium into the BHA target, a film with a higher degree of crystallinity could be obtained, as compared to undoped BHA structures. A mix of $10 \%$ commercial bioinert glass and $90 \%$ BHA could produce a film consisting mainly of HA with small 
crystallites ( $48.9 \mathrm{~nm}$ in length vs. $83.5 \mathrm{~nm}$ for BHA:Li and $71 \mathrm{~nm}$ for BHA coatings) and a high degree of anisotropy (D002/D300 = 2.1 vs. 1.49 in the case of BHA:Li and 1.34 in the case of BHA coatings) [53].

In FTIR investigations, bands characteristic to carbonate groups were identified both in targets and films made of BHA. The lines peaking at $\left(1419,1457\right.$, and $1544 \mathrm{~cm}^{-1}$, respectively) were characteristic to $\mathrm{C}-\mathrm{O}$ asymmetric stretching and were present in both spectra of targets and films.

In the case of bovine $\mathrm{HA}$ doped with $\mathrm{MgF}_{2}$ (BHA:MgF) structures [54], the dopant indirectly induced the presence of $\mathrm{MgO}$ traces caused during sintering of the targets by partial oxidation of $\mathrm{MgF}_{2}$. The amount of $\mathrm{MgF}_{2}$ in targets was of $2 \%$ and the amount transformed in $\mathrm{MgO}$ was estimated to be of $0.4 \mathrm{wt} . \%$. However, in films, peaks of $\mathrm{MgF}_{2}$ were not identified, but only supplemental weak $\mathrm{MgO}$ peaks were observed. This can hint toward the possible structural substitution of the $\mathrm{Mg}^{2+}$ cations (in the $\mathrm{Ca}^{2+}$ sites) and $\mathrm{F}^{-}$anions (in the $\mathrm{OH}^{-}$group sites) into the $\mathrm{HA}$ lattice during the deposition process. By incorporating $\mathrm{MgF}_{2}$ in the BHA structure, the HA crystallites' length was reduced from 152 to 100 $\mathrm{nm}$, while the ratio between length and width, D300/D002, dropped from 1.47 to 1.11. Mihailescu et al. [54] also inserted $5 \mathrm{wt} . \% \mathrm{MgO}$ in BHA targets and observed that, in this case, crystallites length increased from 152 to $170 \mathrm{~nm}$. The D300/D002 dropped from 1.47 to 1.20.

One notes that, in the case of $\mathrm{MgF}_{2}$ doping, FTIR investigations revealed the disappearance of the $(\mathrm{OH})^{-}$bands from the synthesized coatings. Moreover, supplemental vibration bands have been recorded at $\sim 876$ to $873 \mathrm{~cm}^{-1}$, which is ascribed to the overlapping of the characteristic peaks of $\left(\mathrm{HPO}_{4}\right)^{2-}$ and $(\mathrm{CO} 3)^{2-}$ groups.

\section{Preparation of Materials}

\section{Powder Preparation}

It is important to mention that all the experimental procedures used for the fabrication of animal-origin HA materials are conducted in accordance with the European Regulations [28] and ISO 22442-1 standard [29].

\subsubsection{Extraction of HA from Mammalian Bones}

BioHA, is usually extracted from bones and teeth of various animals. To obtain the raw materials, cortical bones originating from bovines or swine are the choices generally reported in various studies tackling the extraction of natural/biological HA [2,41]. Two possible explanations for this preference might be advanced: (i) the immediate availability of cow and sheep bones in commercial shops and abattoirs to the difference of more exotic sources such as marine animals, and (ii) the extracellular matrix of bovine bones is mainly composed of HA nanocrystals and collagen fibers. The bones represent $11 \%$ of pork, $15 \%$ of beef, and $16 \%$ of sheep carcasses, respectively. Due to human consumption of these animals' meat, billions of tons of such by-products are generated every year. Moreover, millions of tons of eggshells are thrown out as waste material yearly. Part of these by-products are repurposed as ingredients for pet food, fertilizers, or in pharmaceutic and cosmetic industries. Their applicability can be increased to the biomedical sector, where bones can be used as grafts, scaffolds, or as raw materials for the production of HA for coating of implants [2,55].

BioHA powders are usually obtained from the cortical part of the femoral bones of freshly slaughtered animals (received from slaughter houses, which use the other animal parts for general consumption) [11]. Bones are generally delivered on ice to laboratories and, before use, they are submitted to a veterinary control. HA derived from animal bones is generally prepared following a three-step procedure: (i) mechanical cleaning of soft tissue, (ii) deproteinization in the alkali media, and (iii) calcination at temperatures sufficiently high to remove any remnant organic and biological hazardous components. Additionally, all bones are thoroughly washed and/or boiled with distilled water. After this preliminary step of washing and drying, the bones are cut off, gently checked for any remnant ligaments and soft tissues and further processed. Next, bone marrows are extracted, and all other unwanted soft tissue residues or macroscopic adhering impurities and substances are removed 
from shafts. Then, the shafts are cut off into slices, cleaned, and washed with distilled water. Cleaned parts are deproteinized in either sodium hypochlorite, hydrogen peroxide, diammonium hydrogen phosphate, acetone, or $\mathrm{NaOH}$ solutions [56-59]. After washing and drying, for the calcination process, the bone pieces are heated in a furnace (at various temperatures ranging from $350{ }^{\circ} \mathrm{C}$ to $1400{ }^{\circ} \mathrm{C}$, for 1 to $18 \mathrm{~h}$ in air (Table 3), in order to completely remove the organic matter from the bones. One should emphasize that the as-prepared powders are biologically safe due to the high temperature fabrication route, which not only favors the crystallization of the material, but also completely prevents any risk of diseases transmission, since no pathogen can survive to such extreme conditions $[25,53,54,60]$. The resulting calcined bone specimens are cooled to room temperature (RT) by slow furnace cooling. Then, they are generally crushed inside an agate crucible, using a mortar and pestle, prior to undergoing ball-milling to fine powders (i.e., with particles of submicron size).

Figueiredo et al. [61] performed a comparative study of the structural and chemical properties of both human and animal bone-derived HA, submitted to different calcination temperatures (600, 900 , and $1200{ }^{\circ} \mathrm{C}$, respectively). The obtained results indicated that the calcination temperature strongly influenced the properties of the bone samples. At higher temperatures, pure HA could be obtained, which presents higher crystallinity degrees, larger crystallite sizes, and a less porous structure. Figueiredo et al. concluded that the mammalian bone samples calcined at $600{ }^{\circ} \mathrm{C}$ exhibited the most promising combination of chemical composition and structure that could be exploited to provide good alternatives to synthetic apatite and/or allogeneic bone.

The viability of producing biogenic HA from bio-waste animal bones (bovine, caprine, and galline), by heat treatments in air atmosphere at different temperatures $\left(600-1000{ }^{\circ} \mathrm{C}\right)$ was demonstrated by Ramesh et al. [62]. Among the three types of investigated animal bones, it was demonstrated that the bovine-derived HA was stable for all investigated temperatures, while those produced from both caprine and galline bones exhibited signs of decomposition, with the appearance of the $\beta$-TCP phase at temperatures beyond $700{ }^{\circ} \mathrm{C}$. In addition, the bovine and caprine bones presented hardness values comparable with the ones of the human cortical bone, while, for galline bone samples, higher porosity levels and low hardness values were inferred.

Akyurt et al. [63] produced HA from sheep teeth, by calcination and sintering at different temperatures $\left(1000-1300^{\circ} \mathrm{C}\right)$. Compression strength and microhardness measurements were performed and the obtained results were the best in the case of samples sintered at $1300{ }^{\circ} \mathrm{C}$. This behavior was attributed to the F-content presence in the enamel structure.

Gheisari et al. [64] prepared natural HA-Hardystonite (HT) ceramics with different percentages of HT $(5,10$, and $15 \mathrm{wt} . \%$, respectively). Their results showed that the mechanical properties of HA increased and the bioactivity behavior improved with the addition of HT to natural HA. The maximum value of the density was inferred for the $10 \mathrm{wt} . \%$ HT samples, which was attributed to the formation of HT silicate phases between the matrix particles and formation of glass bonds. Moreover, the 15 wt.\% HT nanocomposite samples had the lower cold crushing strength as compared to the other ones investigated in the paper, which was due to the overlapping of glass bonds. Simulated body fluid test results indicated that the Si content increased in the samples with a higher amount of HT. Consequently, the number of $\mathrm{Si}-\mathrm{OH}$ nucleation sites expands and the formation of apatite layers takes place along with an increase in the ceramics' bioactivity. In a similar study, Khandan et al. [65] reported on natural HA-diopside (Di) bio-ceramics, with different Di content (10, 20, and $30 \mathrm{wt} . \%$, respectively). The obtained results indicated that an elevated content of Di in the samples determined an increase of both the density on the surface and the adhesion values. In order to maintain a surface free of cracks, Khandan et al. indicated the optimum values for voltage, time, and temperature as being $50 \mathrm{~V}, 10 \mathrm{~min}$, and $850^{\circ} \mathrm{C}$, respectively. 
Barakat et al. [30] proposed in their study three different methods to extract HA from bovine bones, which include thermal decomposition, subcritical water, and alkaline hydrothermal processes. One advantage of the first method was to produce an HA nano-rode rather than the nanoparticles obtained by using the other two proposed methods. However, the morphological investigations illustrated smaller-size particles in the case of subcritical and alkaline hydrothermal processes, as compared to thermal decomposition. Barakat et al. concluded that the proposed methods are simple and cheap, which are two important advantages that might advance their use for large scale applications.

Giraldo-Betancur et al. [66] reported on a physical-chemical comparison of synthetic and biological HA. The bio-HA samples originated from bovine bones and were prepared by using three different treatments (defat, alkaline, and calcination). It was indicated that the calcination and alkaline processes delivered crystalline HA, which presented a comparable quality to the synthetic one. In addition, it was illustrated that the calcination process was appropriate to obtain HA with the minor and major elements that appear in the natural bone tissue. After applying the alkaline process, a crystallinity degree greater than $62 \%$ was detected. Moreover, the surface of the alkaline sample presented a transition behavior between dense and porous morphology. In a similar study, Rincón-López et al. [67] performed a comparative study on the physical-chemical properties and biological behavior of sintered-bovine-derived HA and commercial HA. It was demonstrated that highly crystalline HA could be obtained from bovine bones. One should note that the $\mathrm{Na}^{+}$and $\mathrm{Mg}^{2+}$ ions intrinsically presented in HA of bovine origin seemed to influence the sintering behavior evolving to ceramics with lower porosity and coarser microstructure compared to those obtained with synthetic HA. Both these studies indicated the possibility to use HA derived from bovine bones as a viable alternative to synthetic HA for biomedical applications.

In Table 3, the details for HA powder preparation using mammalian sources are summarized.

The colour of the resulting powders (Table 3 ) is either milky-white or green.

For more information on BioHA extraction methods from mammalian bones, the reader can consult additional information contained in references from Table 3. 
Table 3. Preparation of HA powders derived from mammalian bones, presented in the order of the calcination temperature.

\begin{tabular}{|c|c|c|c|c|c|}
\hline \multirow{2}{*}{ Source Material } & \multirow{2}{*}{ Pre-Treatment } & \multicolumn{2}{|c|}{ Calcination } & \multirow{2}{*}{ Dopants } & \multirow{2}{*}{ Reference } \\
\hline & & {$\left[{ }^{\circ} \mathrm{C}\right]$} & Time [min] & & \\
\hline Bovine bones (femur) & Immersion in 2.6 wt.\% sodium hypochlorite solution for 14 days & - & - & - & [68] \\
\hline Bovine bones (femur) & $\begin{array}{l}\text { Boiling in distilled water for } 2.5 \mathrm{~h} \text {, ultrasonication with acetone for } 5 \\
\text { min, dried at } 120^{\circ} \mathrm{C} \text { for } 12 \mathrm{~h} \text { in an oven }\end{array}$ & $350-900$ & 180 & - & [69] \\
\hline Bovine bones & $\begin{array}{l}\text { Boiling in deionized water for } 30 \mathrm{~min} \text {, petroleum ether with constant } \\
\text { agitation at } 30^{\circ} \mathrm{C} \text { and sodium hydroxide solution, drying in a } \\
\text { vacuum oven at } 1.33 \mathrm{~Pa} \text { and } 70^{\circ} \mathrm{C} \text { for } 5 \mathrm{~h}\end{array}$ & $400-900$ & 180 & - & [66] \\
\hline Bovine bones (femur) & Boiling water followed by sun drying & $500-1400$ & $120-240$ & - & [70] \\
\hline $\begin{array}{l}\text { Bovine, caprine, and galline } \\
\text { bones }\end{array}$ & $\begin{array}{l}\text { Autoclave at } 100^{\circ} \mathrm{C} \text { for } 1 \mathrm{~h} \text {, rinsing with water and drying for } 3 \mathrm{~h} \text { at } \\
70^{\circ} \mathrm{C} \text { in a box oven }\end{array}$ & $600-1000$ & 120 & - & {$[62]$} \\
\hline Bovine bones & Applying direct flame from a gas torch to the cleaned bones & $600-1100$ & 180 & - & [71] \\
\hline Bovine bones & Boiling with water for 2 to $3 \mathrm{~h}$, drying in an oven at $80^{\circ} \mathrm{C}$ for $72 \mathrm{~h}$ & $600-1100$ & 180 & - & [72] \\
\hline Human, bovine, porcine bones & $\begin{array}{l}\text { Boiling in distilled water for } 30 \mathrm{~min} \text {, immersion in ethanol, hydrogen } \\
\text { peroxide, formaldehyde solution, drying in a vacuum oven at } 50^{\circ} \mathrm{C} \\
\text { for three days }\end{array}$ & $600-1200$ & 1080 & - & {$[61]$} \\
\hline Bovine bones & $\begin{array}{l}\text { Immersion for } 14 \text { days in an alkali solution of } 1 \% \text { sodium } \\
\text { hypochlorite }\end{array}$ & 700 & 240 & $\begin{array}{l}1 \text { wt. } \% \mathrm{Li}_{2} \mathrm{CO}_{3} \\
1 \text { wt. } \% \mathrm{Li}_{3} \mathrm{PO}_{4}\end{array}$ & {$[60]$} \\
\hline Bovine bones & Washing by water and acetone, drying at $160^{\circ} \mathrm{C}$ for $48 \mathrm{~h}$ & 750 & 360 & - & {$[30]$} \\
\hline Bovine bones & Boiling in distilled water for $8 \mathrm{~h}$, drying overnight at $200^{\circ} \mathrm{C}$ & 800 & 180 & - & [73] \\
\hline Bovine bones (femur) & Keeping in boiling distilled water for $2 \mathrm{~h}$, heated at $60^{\circ} \mathrm{C}$ for $24 \mathrm{~h}$ & 800 & 120 & - & [74] \\
\hline Bovine bones & $\begin{array}{l}\text { Boiling for } 15 \mathrm{~min} \text {, filtrating, washing with distilled water for several } \\
\text { times and drying at } 100^{\circ} \mathrm{C} \text { in a vacuum oven for } 48 \mathrm{~h}\end{array}$ & $800-1100$ & 180 & - & [75] \\
\hline Ovine and bovine bones & $\begin{array}{l}\text { Immersion for } 14 \text { days in an alkali solution of } 1 \% \text { sodium } \\
\text { hypochlorite }\end{array}$ & 850 & 240 & $1.5 \mathrm{wt} . \% \mathrm{Ti}$ & [53] \\
\hline Veal bones & $\begin{array}{l}\text { Sodium hydroxide solution in a beaker, neutralization with distilled } \\
\text { water, drying in an oven }\end{array}$ & 850 & 180 & - & [64] \\
\hline
\end{tabular}


Table 3. Cont.

\begin{tabular}{|c|c|c|c|c|c|}
\hline \multirow{2}{*}{ Source Material } & \multirow{2}{*}{ Pre-Treatment } & \multicolumn{2}{|c|}{ Calcination } & \multirow{2}{*}{ Dopants } & \multirow{2}{*}{ Reference } \\
\hline & & {$\left[{ }^{\circ} \mathrm{C}\right]$} & Time [min] & & \\
\hline Calf bones & $\begin{array}{l}\text { Sodium hydroxide solution in a beaker, neutralization with distilled } \\
\text { water, drying in an oven }\end{array}$ & 850 & 180 & - & {$[65]$} \\
\hline Bovine bones (femur) & $\begin{array}{l}\text { Cleaning and washing with distilled water, immersion for } 14 \text { days in } \\
\text { an alkali solution of } 1 \% \text { sodium hypochlorite }\end{array}$ & 850 & 240 & $\begin{array}{l}1 \text { wt. } \% \text { of } \mathrm{Li}_{2} \mathrm{CO}_{3} \\
\text { and } \mathrm{Li}_{3} \mathrm{PO}_{4}\end{array}$ & [11] \\
\hline Bovine bones & Washing by water and acetone, drying at $160^{\circ} \mathrm{C}$ for $48 \mathrm{~h}$ & 850 & 60 & - & [76] \\
\hline Bovine bones & Boiling and sun drying & 900 & 120 & - & [77] \\
\hline Bovine bones & Boiling in distilled water for $3 \mathrm{~h}$, drying in an oven at $100^{\circ} \mathrm{C}$ for $24 \mathrm{~h}$ & 900 & 120 & - & [78] \\
\hline Bovine bones (femur) & $\begin{array}{l}\text { Immersion for } 14 \text { days in an alkali solution of } 1 \% \text { sodium } \\
\text { hypochlorite }\end{array}$ & 1000 & 240 & $\begin{array}{l}5 \text { wt. } \% \mathrm{MgO} \\
2 \text { wt. } \% \mathrm{MgF}_{2}\end{array}$ & {$[54]$} \\
\hline Ovine dentine bones & Cleaning and washing, drying at $750{ }^{\circ} \mathrm{C}$ for $5-6 \mathrm{~h}$ & 1000 & 240 & 1.5 wt. $\% \mathrm{Ti}$ & [25] \\
\hline $\begin{array}{l}\text { Camelus dromedarius bones } \\
\text { (femur) }\end{array}$ & $\begin{array}{l}\text { Boiling in distilled water } \\
\text { for } 1 \mathrm{~h} \text {, washing with a strong water jet, drying at } 100{ }^{\circ} \mathrm{C} \text {, for } 60 \mathrm{~min} \text {, } \\
\text { drying at RT for } 7 \text { days, immersion in acetone for } 1 \mathrm{~h} \text {, washing with } \\
\text { distilled water }\end{array}$ & 1000 & 180 & - & [79] \\
\hline Sheep teeth & Cleaning and washing, drying at $750^{\circ} \mathrm{C}$ for 5 to $6 \mathrm{~h}$ & $1000-1300$ & 240 & - & {$[63]$} \\
\hline $\begin{array}{l}\text { Human dentine, ovine, and } \\
\text { bovine bones }\end{array}$ & $\begin{array}{l}\text { Immersion for } 14 \text { days in an alkali solution of } 1 \% \text { sodium } \\
\text { hypochlorite }\end{array}$ & 1100 & 240 & - & {$[80]$} \\
\hline Bovine bones & $\begin{array}{l}\text { Boiling in deionized water for } 30 \mathrm{~min} \text {, petroleum ether with constant } \\
\text { agitation at } 30^{\circ} \mathrm{C} \text { and sodium hydroxide solution, drying in a } \\
\text { vacuum oven at } 1.33 \mathrm{~Pa} \text { and } 70^{\circ} \mathrm{C} \text { for } 5 \mathrm{~h}\end{array}$ & 1200 & $120-240$ & - & [67] \\
\hline Bovine bones & $\begin{array}{l}\text { Boiling in distilled water for } 2 \mathrm{~h} \text {, heating in an electrical furnace at } \\
500{ }^{\circ} \mathrm{C} \text { for } 6 \mathrm{~h}\end{array}$ & 1200 & 240 & - & [81] \\
\hline
\end{tabular}




\subsubsection{Extraction of HA from Fish Sources}

Even though fish bones represent a rich source of calcium, phosphate, and carbonate [2], there are scarce reports on HA synthesis from these natural sources for biomedical applications [82]. In general, fish bones originate from fisheries, which capture fish and use it mainly for obtaining meat, oil, or some low-value fertilizers [2]. The fish bones are collected after gently removing the flesh parts from the entire fish. The bones are washed with a hot water jet or steam to remove all types of proteins and other organic impurities. The cleaned bony parts are further treated with reagents such as $\mathrm{NaOH}$ [83]. Similar to the case of mammalian bones, after washing and drying, the bone pieces are subjected to heating at various temperatures ranging from 100 to $1200{ }^{\circ} \mathrm{C}$, for 1 to $12 \mathrm{~h}$ in air (see Table 4), to completely eliminate any organic matter from the bones. The resulting calcined fish bone specimens are cooled to RT by slow furnace cooling. Afterward, the specimens are either hand-crushed with a mortar and pestle or ball-milled to fine powders (Table 3). One notes that the color of the resulting powders (Table 4) is white.

Table 4. Preparation of HA powders derived from fish sources, presented in order of the calcination temperature.

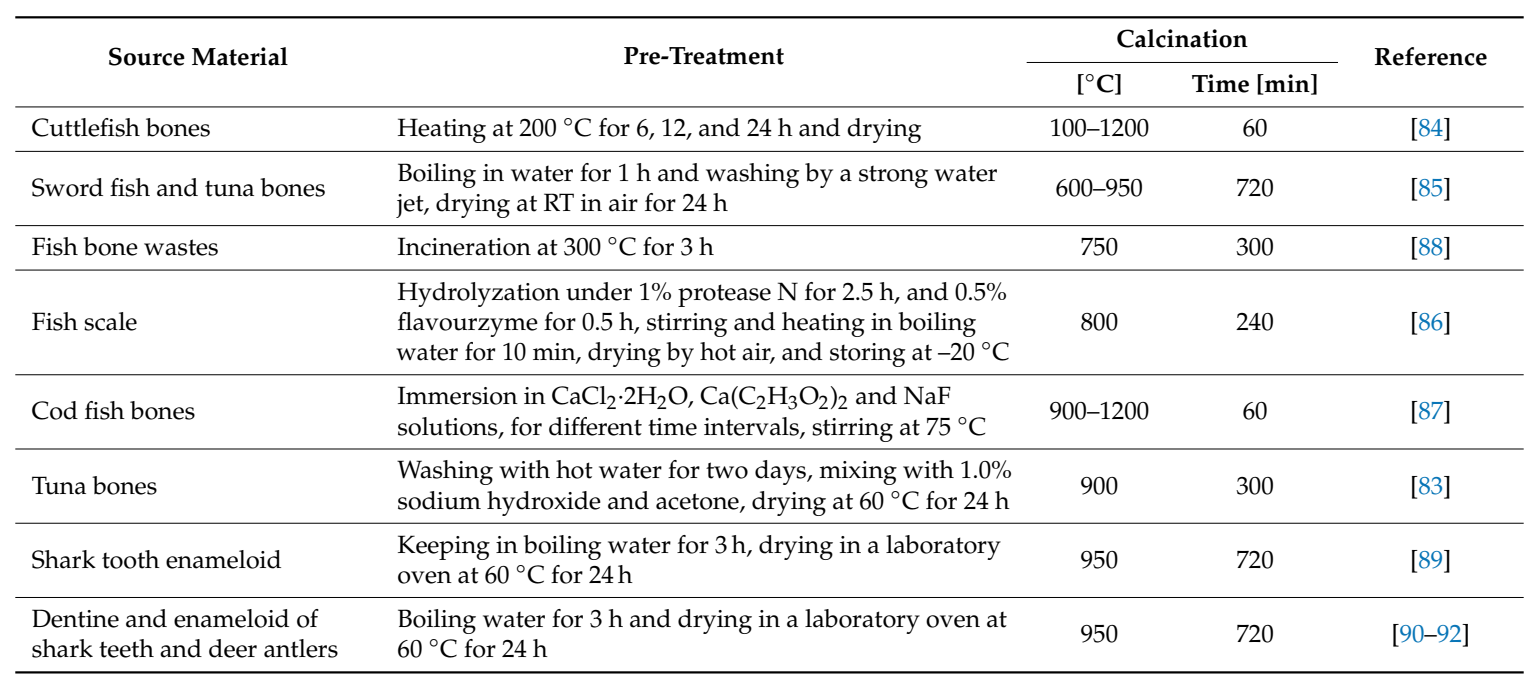

Venkatesan et al. [83] isolated HA from fish sources by applying alkaline hydrolysis and thermal calcination methods. An increase in the particle size from 0.3 to $1.0 \mu \mathrm{m}$ was observed when using the thermal calcination method, which is due to the particle agglomeration. HA obtained by the second method are of a nanorod shape, with 17-71 $\mathrm{nm}$ in length and 5-10 nm in width. Thermal calcination, in comparison to alkaline hydrolysis, produced HA with a higher crystallinity degree.

Kannan et al. [84] used hydrothermal transformation of aragonitic cuttlefish bones at $200{ }^{\circ} \mathrm{C}$ and calcination at temperatures up to $1200{ }^{\circ} \mathrm{C}$ to produce porous HA scaffolds with different levels of fluorine substitution ( $46 \%$ and $85 \%$ ) on the $\mathrm{OH}$ sites. The $\mathrm{F}$ incorporation in the HA lattice determined a lowering of the unit cell volume because of the reduction of the $a$-axis length. The crystallites formed were close in size to bone-like apatite and were orientated along the $a$-axis rather than the $c$-axis. An type-AB carbonated apatite was also detected.

Boutinguiza et al. [85] reported on BioHA obtained from sword and tuna fish bones. The prepared powders consisted of a B-type carbonate $\mathrm{HA}$ with a $\mathrm{Ca} / \mathrm{P}$ ratio higher than that of stoichiometric $\mathrm{HA}$ due to carbonate ions substituting phosphates. The presence of minor elements such as $\mathrm{Na}, \mathrm{K}, \mathrm{Mg}$, and Sr substituting Ca was also indicated. The calcination treatment performed at $600{ }^{\circ} \mathrm{C}$ delivered a B-type carbonated HA. When reaching $950{ }^{\circ} \mathrm{C}, \beta$-TCP was present in a minor amount and the carbonate content decreased. This indicated a partial decomposition of the material. It was concluded that these fish bone-derived materials originate from sustainable and cheap sources and could, therefore, represent a promising future alternative to synthetic HA for medical applications. 
Huang et al. [86] compared the composition and biological properties of bio-waste HA derived from fish scale with those of synthetic HA. The experimental results indicated that the fish HA materials presented nano-sized particles with a high $\mathrm{Ca} / \mathrm{P}$ ratio. Compared to synthetic $\mathrm{HA}$, the sintering process increased porosity and surface roughness for fish-derived HA. The alkaline phosphate assay and von Kossa staining demonstrated that the fish-HA particles promoted osteogenic differentiation and mineralization of MG63 cells. Taking into account these results, one should recommend fish scales as a cost-effective and environmentally-friendly source for producing HA.

Piccirillo et al. [87] produced apatite-based and tricalcium phosphate-based materials from codfish bones, by annealing at temperatures between $900{ }^{\circ} \mathrm{C}$ and $1200{ }^{\circ} \mathrm{C}$. Single phase HA, chlorapatite, and fluorapatite were obtained using $\mathrm{CaCl}_{2}$ and $\mathrm{NaF}$ solutions, respectively. One should note that this was the first study to report on compositional modifications of natural origin materials used to tailor the relative concentrations of elements. The obtained results indicated that, by using a simple and effective valorization technique, the conversion of this by-product into a viable compound for biomedical applications can be attained.

In Table 4, the details for HA powder preparation using fish resources are summarized.

For more information on BioHA extraction methods from fish sources, the reader can consult additional information contained in references from Table 4 .

\subsubsection{Extraction of HA from Biogenic Sources}

Every year, impressive quantities of biogenic resources such as eggshells, sea shells, and other calcite materials are disposed of as waste by restaurants, hatcheries, bakeries, or homes [2]. Due to the fact that they are very cheap and accessible, eggshells represent an important source of calcium precursor required for the synthesis of HA.

In general, the preparation procedure to extract $\mathrm{CaO}$ from shells consists first in washing them with boiling water or steam to completely remove all impurities. In the next step, the shells are crushed to fine powders, which is followed by heating at elevated temperatures. The resulting $\mathrm{CaO}$ reacts with phosphorous precursors to prepare HA by following a protocol detailed in Reference [93].

Starting from eggshells, Elizondo-Villarreal et al. [94] synthesized HA using a simple hydrothermal approach. The obtained product was a mixture of $\mathrm{HA}$ and $\mathrm{CaHPO}_{4}$ in a 3:1 ratio, with $\mathrm{HA}$ morphology in the form of whiskers. It was concluded that the obtained physical-chemical characteristics of HA should advance this type of material for dental prosthesis applications.

HA was prepared by Chaudhuri et al. [95] from eggshells and a solvent such as dipotassium phosphate. An appropriate amount of eggshells-derived $\mathrm{CaO}$ was immersed in $\mathrm{K}_{2} \mathrm{HPO}_{4}$ solution, for different soaking times, to obtain nanocrystalline HA. Both grain size and $\mathrm{pH}$ indicated a slight decreasing tendency with increasing soaking time. The lattice strain also showed similar behavior with increasing soaking time. The proposed procedure for the low-temperature synthesis of large-scale HA is rather simple, low cost, and eco-friendly.

Tamasan et al. [96] reported on the preparation and characterization of powders consisting of the different phases of CaPs obtained from marine-origin raw materials of sea-shells (Sputnik sea urchins and Trochidae I. concavus) in reaction with $\mathrm{H}_{3} \mathrm{PO}_{4}$. In the developing CaP powders, hot-plate, and ultrasound methods were used. In the Sputnik sea urchins samples, brushite was found to be predominant, while calcite was shown to exist as a small secondary phase. For the second analyzed material, monetite and HA phases were identified. A thermal treatment performed at $850{ }^{\circ} \mathrm{C}$ resulted in flat-plate whitlockite crystals $(\beta-\mathrm{MgTCP})$ for both samples, regardless of the fabrication method.

Gunduz et al. prepared biphasic bioceramic nano-powders of HA and $\beta$-TCP [97] from shells of a sea snail, by using a novel mechano-chemical method. When compared to the conventional hydrothermal method, this chemical method is simple and economic, due to inexpensive and safe equipment. The characteristics of the as-produced powders, along with their biological origin, should advance these materials for further consideration and experimentation to fabricate nanoceramic biomaterials. 
In Table 5, the details for HA powder preparation using biogenic resources are summarized.

Table 5. Preparation of HA powders derived from biogenic sources, presented in the order of the calcination temperature.

\begin{tabular}{|c|c|c|c|c|}
\hline \multirow{2}{*}{ Source Material } & \multirow{2}{*}{ Pre-Treatment } & \multicolumn{2}{|c|}{ Calcination } & \multirow{2}{*}{ Reference } \\
\hline & & {$\left[{ }^{\circ} \mathrm{C}\right]$} & Time [min] & \\
\hline Shell of sea snail & $\begin{array}{l}\text { Cleaning thoroughly from sand particles and other } \\
\text { foreign materials, drying, solution of } \mathrm{H}_{3} \mathrm{PO}_{4} \text {, hot-plate } \\
\text { stirring at } 80^{\circ} \mathrm{C} \text { for } 8 \mathrm{~h} \text {, filtration, and drying at } 100{ }^{\circ} \mathrm{C} \\
\text { overnight in an incubator. }\end{array}$ & $400-800$ & 240 & [97] \\
\hline $\begin{array}{l}\text { Sputnik Sea urchin and sea } \\
\text { snail shells }\end{array}$ & Heating on a hotplate at $80^{\circ} \mathrm{C}$ for $15 \mathrm{~min}$ & $450-850$ & 240 & [96] \\
\hline Chicken eggshells & $\begin{array}{l}\text { Cleaning with distilled water and keeping into } 1 \mathrm{M} \\
\mathrm{H}_{2} \mathrm{O}_{2} \text { solution for a week, drying at } 90^{\circ} \mathrm{C}\end{array}$ & 700 & 300 & [94] \\
\hline Egg shell & $\begin{array}{l}\text { Cleaning and washing with flowing distilled water, } \\
\text { drying at } 300^{\circ} \mathrm{C} \text { for } 1 \mathrm{~h}\end{array}$ & $850-900$ & 180 & [95] \\
\hline Eggshells & Cleaning in boiling water & 900 & 120 & [98] \\
\hline Hen eggshell & $\begin{array}{l}\text { Stripping the membrane off the eggshell, rinsing with } \\
\text { water, drying }\end{array}$ & 1000 & 180 & [99] \\
\hline
\end{tabular}

For more information on BioHA extraction methods from biogenic sources, the reader can consult additional information contained in references from Table 5.

\section{Pulsed Laser Deposition Method}

\subsection{Method Overview}

To the difference of wet synthesis methods, plasma-assisted techniques offer important advantages, such as: (i) a much faster process for surface deposition, (ii) industrial scaling, (iii) a stoichiometric transfer of the target composition in the synthesized structures, (iv) a better uniformity in terms of morphology and composition, $(v)$ a lower porosity, and $(v i)$ a decreased tendency of the deposited structures to crack or delaminate $[100,101]$. In the biomedical domain, for the fabrication of CaP coatings for bone implant applications, the most applied plasma-assisted techniques are radio-frequency magnetron sputtering and PLD [102].

PLD is a thin films synthesis technique consisting of the ablation by a focused, high power, pulsed laser beam of a solid target in a vacuum environment and the condensation of the resulting vapor phase on a deposition substrate placed parallel to the holder [19]. The most basic set-up consists of a vacuum chamber, a laser source, a focusing lens, a target holder rotated by a motor, and a substrate usually placed on a heater with the role to increase film adherence and promote crystallinity.

The wavelengths of choice for the laser sources used for ablation are in the UV range due to the higher penetration depth of this type of beam in the target material as compared to visible or IR laser sources and higher photon energy that allows for a more efficient vaporization of the target [103]. Popular laser sources used in PLD experiments are excimer lasers such as ArF [104], KrF [105], or $\mathrm{XeCl}$ [106] emitting at 193, 248, or $308 \mathrm{~nm}$, respectively, or a solid-state laser such as a Nd:YAG [107], which emits at $266 \mathrm{~nm}$.

To increase the amount of evaporated target material to the detriment of expulsed liquid or solid phases, lasers emitting in a pulsed regime, with pulse durations in the nanoseconds-picoseconds range, are generally used [108]. In these regimes, the absorption process occurs on a much shorter time-scale as compared to the thermal diffusion process. The surface layers of the target reach temperatures of tens of thousands of $\mathrm{K}$ and are instantly vaporized. A plasma plume consisting of atoms, ions, electrons, molecules, free radicals, and condensed particles expands at supersonic speed and is accelerated toward the substrate (on a direction perpendicular on the target), where the deposition takes place [109].

If a solid collector is placed in front of the target at a distance approximately equal to the plasma plume's length, the material condenses and, pulse-by-pulse, a thin film is grown [110]. If the placement 
of the substrate is closer to the target than the plasma plume's length, the material will be deposited and, subsequently, washed by the plasma plume, with the deposition being inefficient and uncontrollable. Similarly, if the distance is larger than the plume's length, the deposition will also be inefficient, since the film thickness is inversely proportional to the square of the target-to-substrate distance. Femtosecond laser sources are not considered optimal for thin film synthesis. Due to the high energy of the ablated species, the growing film is heavily bombarded by high speed particles, which makes the process inefficient and results in films with defects, vacancies, or made of small solid particles ripped from the target surface [111].

Due to the high temperatures generated on the target surface, any type of material can be ablated and, therefore, a wide variety of targets can be used for thin film deposition.

The technique is versatile in terms of process output. By independent control of the deposition temperature, background pressure, and substrate positioning, one can change the film's crystallinity, composition, adherence, surface roughness, and/or thickness [18]. The use of multiple targets irradiated subsequently allows for the deposition of multi-layered structures [112].

Moreover, the PLD technique can be easily adapted to increase the range of applications: by limiting the number of pulses, one can deposit nanoparticles instead of thin films [113]. Two targets of different materials can be irradiated simultaneously and the intermixing plasma plumes can create a compositional library on a substrate [114]. By irradiating a frozen target made from an organic compound dissolved into a matrix material, an organic thin film can be laser deposited without degradation of the target material in a variation of the method, denominated MAPLE, i.e. Matrix Assisted Pulsed Laser Evaporation [115].

The film growth by PLD also offers different types of advantages over other deposition techniques, such as:

- The irradiation source is situated outside the deposition chamber, which offers a high degree of flexibility in using the material, set-up, and adjustment of deposition parameters;

- most solid materials can be laser ablated and deposited as films;

- due to the laser operating in a pulsed regime, the film growth rate can be controlled with a highly precise degree $\left(10^{-2}-10^{-1} \mathrm{~nm} /\right.$ pulse);

- in optimal conditions, the stoichiometry of the deposited layer coincides with the one of the targets, even for very complex materials with a high degree of instability;

- the high energy of ablated species determines the synthesis of extremely adherent layers;

- one can obtain species with electronic states different from the equilibrium ones and new, metastable phases of the material;

- $\quad$ even though their thickness might have very low values, the films uniformly cover the substrate and prevent the release of ions from the implant into the body;

- when reducing the thickness, the risk of delamination decreases.

Like all the other synthesis techniques, PLD presents some disadvantages too, such as a low deposition rate, an applicability domain limited to compounds that are not sensible to thermal decomposition and degradation that appears during processing by prolonged exposure to UV laser radiation, the presence of droplets (of a different composition and dimensions), and a low deposition area (no bigger than a few $\mathrm{cm}^{2}$ ). The last two drawbacks can be diminished or even eliminated by additional set-ups $[18,116]$.

\subsection{BioHA Targets Preparation}

The powders obtained following the protocols mentioned in Section 4 are generally pressed and the resulting pellets are heat-treated in a furnace, to reach compactness by eliminating air bubbles and water vapors. The as-sintered pellets are compact and tough (Figure 1) and can be used as targets in the PLD experiments $[11,25,53,54,60,80]$. 


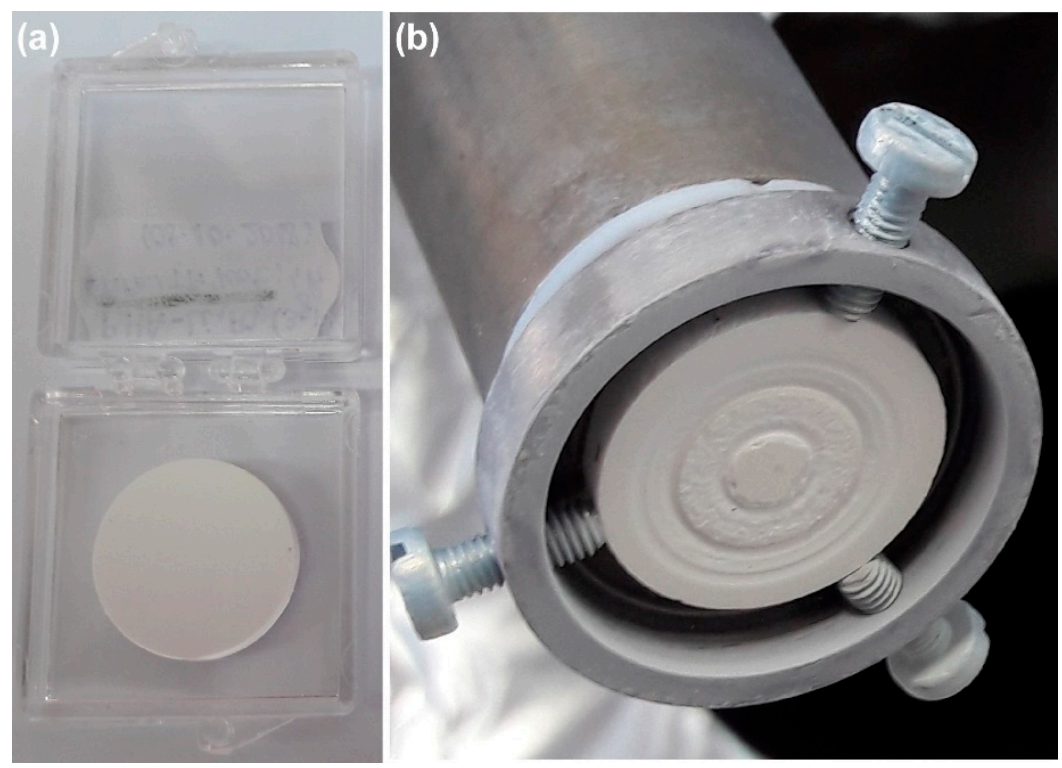

Figure 1. Photos of sintered PLD targets: (a) before and (b) after the action of the beam generated by a $\mathrm{KrF}^{*}$ excimer laser source.

The Importance of Thermal Treatments in the Case of Targets

Even though CaP bio-ceramics possess excellent biomedical characteristics, their poor mechanical behavior determined focused research to find viable solutions to this important drawback.

The properties, efficiency, phase purity, and size distribution of HA extracted from natural resources, especially from bones, depend upon factors like the extraction technique, the calcination temperature, and the nature of bones [2]. HA derived from natural resources (such as animal bones) is available in unlimited supply and can be produced by calcination methods [27,117]. Ozyegin et al. [117] reported that sintered BHA is safe from potentially transmitted diseases such as bovine spongiform encephalopathy ("mad cow disease"). The manufacturing of these powders is easy to carry out and economically viable $[2,117]$. Prions, which are the smallest proteinaceous infectious particles, can resist inactivation by procedures that modify nucleic acids and are able to transmit alone an infectious disease, which causes harm to the host tissue [118]. Thus, the temperature generally applied for calcination is around $850^{\circ} \mathrm{C}$ and it was demonstrated that no disease transmission pathogens (including prions) can survive to such high temperatures $[2,27,117]$. However, a special calcination regime has to be carefully selected in order to remove all organic matter and enhance the crystallinity of HA, while avoiding thermal decomposition of the final product, HA [2].

\subsection{Substrates Used as Pulsed Laser Deposition Collectors}

In general, for the fabrication of bio-implants and bio-devices, there are five classes of materials used: (i) metallic materials, (ii) polymers, (iii) ceramics, (iv) composites, and (v) natural materials.

The most commonly used metals and alloys for medical device applications include stainless steels, cobalt-based alloys, and commercially-pure titanium and its alloys [119]. The last ones are generally preferred for bone-replacement applications mainly due to their intrinsic resistance. These materials have been widely used as endosseous implant materials in dentistry and orthopedics due to their high strength, good corrosion resistance, no allergic problems, low density, and excellent biocompatibility [120]. Moreover, the thin oxide layer, which is naturally formed on their surface, is acting as a protective barrier, which confers its well-known resistance among metals to corrosion in physiological conditions. However, it is far from being an ideal material from a medical point of view because of its insufficient bioactivity when implanted in the human body [121]. 
Polymers represent the largest class of biomaterials, which have gained greater attention due to some important advantages such as (i) ease of fabrication to various complex shapes and structures, (ii) wide range of bulk compositions and physical properties, and (iii) easy tailoring of surface properties [119].

Ceramics are inorganic compounds of metallic or non-metallic materials. When used for skeletal or hard tissue repairing, they are referred to as bio-ceramics. These bio-ceramics can be classified as bioinert (e.g. alumina, zirconia), bioresorbable (e.g. TCP), bioactive (e.g. HA, bioactive glasses, glass ceramics), and porous (e.g. HA coatings on metallic substrates for tissue in-growth).

A composite consists of two or more materials, characterized by a combination of the best physical and chemical characteristics of each component materials. In the biomedical field, composite materials are generally designed for superior mechanical and biological properties. They can be classified as a function of the (i) matrix material and (ii) bioactivity of the composite. In the first case, there are three types of composite materials: (i) polymer matrix composites, (ii) metal matrix composites, and (iii) ceramic matrix composites. For the second case, there are: (i) bioinert composites, (ii) bioactive composites, and (iii) bioresorbable composites.

Collagen and glycosaminoglycans are the most commonly used natural materials for clinical applications [122] due to a series of important advantages, such as: (i) easy recognition by the biological environment due to their similarity with the macromolecular substances, (ii) possibility to by-pass toxicity-related issues, chronic inflammation, or lack of recognition by cells (which generally occurs when dealing with synthetic materials), and (iii) biodegradable nature of the materials, which permits their use for focused applications, where a specific function is needed for a limited period of time [123].

In general, prior to the coating process and immediately after it, special attention needs to be paid to the surface preparation of various types of used substrates. In this respect, different substrate preparation techniques have been reported, from simple to complex ones, with their own peculiarities. Thus, simple substrate preparation procedures include cleaning or degreasing to remove any remnant surface contamination because of manufacturing conditions or improper storage. Solvents like acetone, ethylic alcohol, and/or distilled water might be used in this case, always keeping in mind the nature and properties of the used substrates. By contrast, more complex substrate preparation techniques include (i) mechanical modification of the surface, by sand-blasting [124], grit-blasting [125,126], polishing [127,128], or grinding [129], and (ii) chemical treatments, modifications, or functionalization, using chemical activation [130], alkaline treatments [131], anodization [124,125], acid-etching [124-126], oxidizing [132], and many other actions [124,133]. Additional physical treatments, resulting in various types of surface modifications, were briefly discussed in Reference [133]. After CaP synthesis, the applied post-deposition treatments are intended to (i) provide crystallization/recrystallization of various phases, (ii) improve their fixation to the substrate, and (iii) evaporate traces of solvent(s) that might remain trapped within the deposited structures.

\subsection{Pulsed Laser Deposition Experimental Set-Up}

A PLD experimental set-up is typically composed of a UV laser source, a vacuum stainless-steel deposition chamber (Figure 2), equipped with a rotating target, a fixed substrate holder, and pumping systems. Following target irradiation, a plasma cloud expands, either in vacuum or in different gas atmospheres, and the vapors are collected on substrates (generally placed parallel to the targets and heated up to a temperature in the range of $350-600^{\circ} \mathrm{C}$ ), in the form of thin, adherent films [18]. In this respect, amorphous or crystalline, extremely adherent, stoichiometric, and dense or porous structures from various complex materials can be synthesized, even at relatively low deposition temperatures, by varying the experimental parameters that are mainly related to the (i) laser (fluence, wavelength, pulse-duration, and repetition rate), and (ii) deposition conditions (target-to-substrate distance, substrate temperature, nature, and pressure of the environment) $[19,134,135]$. 


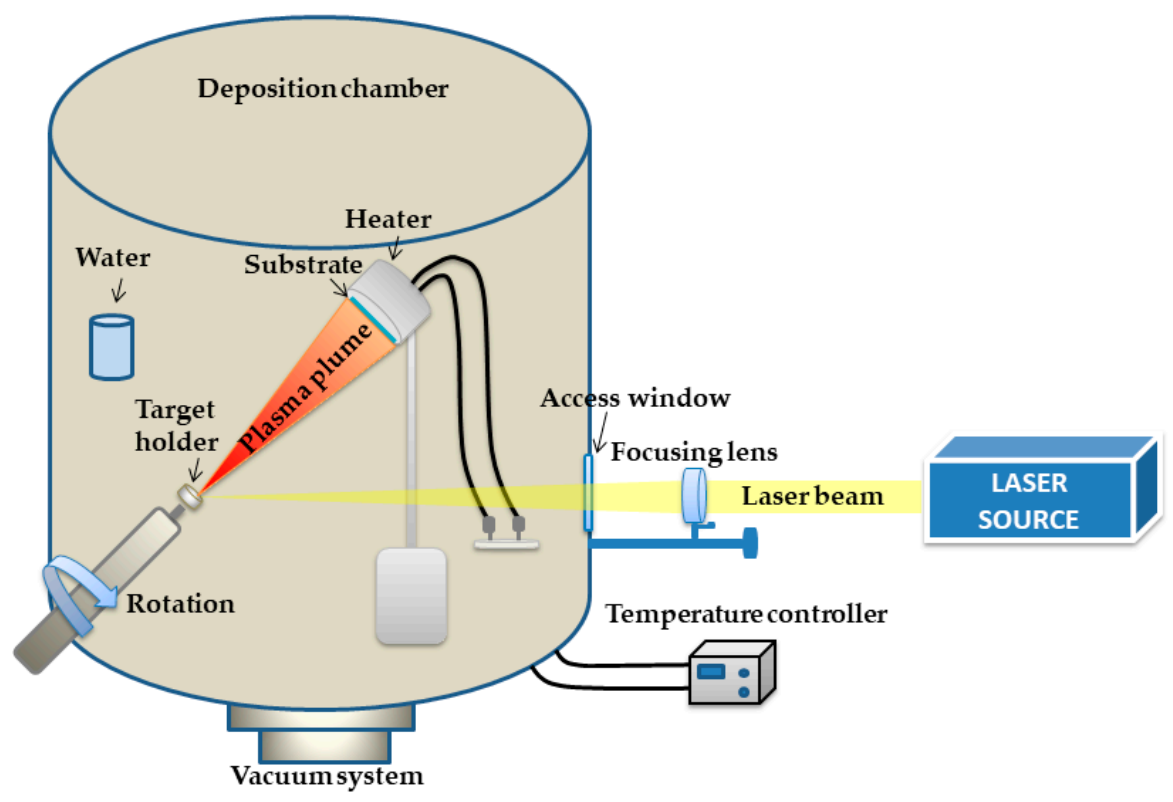

Figure 2. Schematic of an experimental set-up used for PLD synthesis of animal-origin HA coatings.

Due to the possibility to independently vary a large number of parameters (such as the wavelength, fluence, pulse repetition frequency, energy, target preparation, target-to-substrate distance, substrate temperature, area of the laser spot, deposition geometry, nature, and pressure of the gas in the deposition chamber), PLD represents a versatile technique to produce films with a high diversity of morphological and structural characteristics, which are superior to the ones appertaining to conventional deposition techniques (fast processing, safety in functioning, and low production costs) $[18,19,116,136]$.

The substrate temperature during film synthesis by PLD is usually situated in the range of 350 to $600{ }^{\circ} \mathrm{C}$. This way, one can assure the fabrication of highly crystalline and phase-pure films [137]. Moreover, lower or higher values for substrate temperature can be chosen to obtain layers with fine textures or different roughness, with improved adherence to the substrate, depending on the intended applications.

Various experimental conditions used for PLD synthesis of BioHA coatings have been reported in the literature. They are summarized in Table 6 . The results from these papers will be thoroughly analyzed and discussed in Section 6.

Table 6. Different experimental conditions used for PLD synthesis of BioHA coatings.

\begin{tabular}{|c|c|c|c|c|c|c|c|c|}
\hline $\begin{array}{c}\text { HA Source } \\
\text { Material/Used } \\
\text { Substrate }\end{array}$ & $\begin{array}{l}\text { Type of Laser } \\
\text { Used }\end{array}$ & $\begin{array}{c}\text { Target-to-Substrate } \\
\text { Separation } \\
\text { Distance }[\mathrm{cm}]\end{array}$ & $\begin{array}{c}\text { Energy } \\
{[\mathrm{mJ}]}\end{array}$ & $\begin{array}{c}\text { Temperature } \\
\text { during } \\
\text { Deposition }\left[{ }^{\circ} \mathrm{C}\right]\end{array}$ & $\begin{array}{l}\text { Water Vapor } \\
\text { Atmosphere } \\
\text { [mbar] }\end{array}$ & $\begin{array}{c}\text { Pulse } \\
\text { Frequency } \\
{[\mathrm{Hz}]}\end{array}$ & $\begin{array}{c}\text { Number of } \\
\text { Applied Laser } \\
\text { Pulses }\end{array}$ & Reference \\
\hline $\begin{array}{l}\text { Enameloid } \\
\text { of shark teeth/Ti6Al4V } \\
\text { disc }\end{array}$ & $\begin{array}{c}\mathrm{ArF}^{*} \\
(193 \mathrm{~nm})\end{array}$ & - & 320 & 460 & $0.15-0.45$ & 10 & - & [89] \\
\hline $\begin{array}{l}\text { Ovine and bovine } \\
\text { bone/Ti disc and } \mathrm{Si} \\
\text { wafer }\end{array}$ & \multirow{6}{*}{$\mathrm{KrF}^{*}(248 \mathrm{~nm})$} & \multirow{6}{*}{5} & 330 & \multirow{6}{*}{500} & \multirow{6}{*}{0.50} & \multirow{6}{*}{10} & \multirow{6}{*}{15,000} & [53] \\
\hline $\begin{array}{l}\text { Human dentine, } \\
\text { ovine, and bovine } \\
\text { bones/Ti disc and Si } \\
\text { wafer }\end{array}$ & & & 350 & & & & & [80] \\
\hline $\begin{array}{l}\text { Bovine bone/Ti disc } \\
\text { and Si wafer }\end{array}$ & & & & & & & & [54] \\
\hline $\begin{array}{l}\text { Sheep dentine/Ti disc } \\
\text { and Si wafer }\end{array}$ & & & 330 & & & & & [25] \\
\hline $\begin{array}{l}\text { Bovine bone/Ti disc } \\
\text { and Si wafer }\end{array}$ & & & \multirow[t]{2}{*}{360} & & & & & [60] \\
\hline Bovine bone/Ti disc & & & & & & & & [11] \\
\hline
\end{tabular}




\subsection{Thermal Treatments Applied to Pulsed Laser Deposited Coatings}

BioHA coatings are generally amorphous when deposited by PLD. HA loses $(\mathrm{OH})^{-}$molecules and on the deposition substrate a mix of CaPs is formed. The most prominent of them are tricalcium phosphate (TCP) and octacalcium phosphate. The process is reversible and a post-deposition thermal treatment around $500{ }^{\circ} \mathrm{C}$ in water vapors leads to conversion of the deposited amorphous and non-apatite phases into more stable compounds, like HA. In addition, their crystallinity and corrosion resistance increase, and the residual stress is considerably reduced [138-141]. It is also important to note that, the presence of water during the post-deposition heat treatment also plays an important role in this conversion [142,143].

Dinda et al. [144] have reported that a post-deposition thermal treatment at $300{ }^{\circ} \mathrm{C}$ can produce pure, adherent, and crystalline HA coatings, which will not dissolve in simulated body fluids.

Post-deposition thermal treatments, generally performed in air or enriched water-vapor atmospheres, are of key importance. Their role is, on one hand, to restore the stoichiometry of the synthesized compounds and, on the other hand, to improve the overall crystalline status of the coatings [53].

The sintering temperature and atmosphere are considered as important parameters able to tailor the strength and toughness of HA [145]. For example, sintering at elevated temperatures has the tendency to eliminate the functional group $\mathrm{OH}$ in the HA matrix and this would result in the decomposition of the HA phase to form $\alpha$-TCP, $\beta$-TCP, and tetra-calcium phosphate [145].

\section{Characterization of Pulsed Laser Deposited Coatings of Undoped and Doped Animal-Origin Hydroxyapatite}

The purpose of $\mathrm{CaP}$ coatings that cover metallic medical prostheses is to ensure biomimetism, i.e. to "mislead" the human body that the newly implanted device is very similar to its bones and, thus, start osteoblasts proliferation and osseous matrix synthesis. There is no perfect coating technique and the existence of shortcomings for each of them determined the implementation of others, among which PLD is worth mentioning due to its advantages such as stoichiometric transfer and precise thickness control.

For characterization of the PLD synthesized coatings, the most common investigation techniques are: Scanning Electron Microscopy (SEM) for surface morphology and cross-sectional investigations, Energy-dispersive $\mathrm{X}$-ray spectroscopy (EDS) for $\mathrm{Ca} / \mathrm{P}$ ratio determinations, profilometry or Atomic Force Microscopy (AFM) for surface parameters valuation, X-ray diffraction (XRD) for crystalline status, stress, crystallites size, and orientation investigations, Fourier Transform InfraRed (FTIR) spectroscopy for identification of chemical bonds, pull-out bonding strength or scratch tests for assessment of films' adherence to the substrate, and in vitro and in vivo tests. Therefore, we will concentrate in the following sections on these techniques for comparing the morphological, structural, and functional properties of PLD coatings synthesized from targets made of CaPs obtained from animal sources.

\subsection{Morphological and Compositional Analyses}

PLD coatings have general surfaces covered by round particles, which are further denominated as "droplets." Their presence on the surface can be explained like this: following target surface laser irradiation, the surface top layers are instantly vaporized. Part of the pulse energy is transformed into heat, which is concentrated in a subsurface layer. Therefore, due to heat accumulation, a mix of liquid and gaseous phases is generated. A bubble is formed, which expands until the top solid layer breaks and a plasma plume is released. The shockwave of the plume splashes the liquid phase on the target surface and liquid droplets are released with supersonic speeds reaching the substrate. Their number and diameter depend on the type of deposited material as well as pressure in the deposition chamber and on the laser parameters [18]. Droplets can be trapped using ingenious particle captors or off-axis geometries in order to obtain particle-free films. However, in the case of biological applications, a 
rough morphology could be beneficial for osteoblast proliferation and droplet-containing films are considered acceptable.

Sheep derived HA (SHA) coatings synthesized by PLD using a $\mathrm{KrF}^{*}$ excimer laser source [25] also had an irregular morphology composed of spherical particles whose distribution could be approximated by a Gaussian fitting centered around a mean diameter of $1 \mu \mathrm{m}$. The particles size varied between 0.35 to $3.5 \mu \mathrm{m}$. An interesting observation was made for SHA doped with Ti (SHA:Ti, 1.5 wt. $\%$ ) coatings. The particle number on the surface almost doubled as compared to undoped material, which produced rougher surfaces. When depositing coatings with the same number of laser pulses from SHA and SHA:Ti targets, Duta et al. [25] obtained thicker SHA coatings as compared to SHA:Ti ones (1.8 vs. $1.2 \mu \mathrm{m}$, respectively).

In Reference [53], Duta et al. conducted a comparison between film morphology in the case of SHA and BHA doped with $\mathrm{Li}_{2} \mathrm{O}$ or a commercial inert glass. In all cases, the coatings displayed the morphology with round micronic droplets covering the surface. There were no big differences between particles diameter. However, a variation in the number of particles $/ \mathrm{cm}^{2}$ was statistically significant. Table 7 summarizes these differences.

Table 7. Droplets density in the case of synthetic HA and different BioHA coatings synthesized by PLD, using the same experimental conditions.

\begin{tabular}{cc}
\hline Sample Material & Density (Particles/cm $\left.{ }^{\mathbf{2}}\right)$ \\
\hline SHA & $(5.5 \pm 0.8) \times 10^{7}$ \\
BHA:Li & $(11.2 \pm 0.7) \times 10^{7}$ \\
BHA:CIG & $(13.3 \pm 1.1) \times 10^{7}$ \\
HA $_{\text {syn }}$ & $(1.4 \pm 0.5) \times 10^{7}$ \\
\hline
\end{tabular}

The coatings' thickness decreased in the following order: HA $\mathrm{syn}_{\text {, }}$ BHA:Li, SHA, BHA:CIG (3.71 \pm $0.15 \mu \mathrm{m} \rightarrow 3.52 \pm 0.16 \mu \mathrm{m} \rightarrow 2.95 \pm 0.21 \mu \mathrm{m} \rightarrow 2.79 \pm 0.02 \mu \mathrm{m})$. The roughness of the films decreased in the same order with values of $0.76 \pm 0.1$ for $\mathrm{HA}_{\text {syn }}, 0.71 \pm 0.06$ for BHA: $\mathrm{Li}, 0.61 \pm 0.05$ for SHA and $0.77 \pm 0.03 \mu \mathrm{m}$ for BHA:CIG, respectively [53].

To the difference, Mihailescu et al. [54] obtained smooth surfaces of BHA coatings on which a low number of spherical droplets appeared as sputtered. Their diameter ranged from 1.6 to $2.5 \mu \mathrm{m}$. The beginning of an organization of some droplets into clusters could be assumed from the SEM images. For BHA doped with $\mathrm{MgF}_{2}$ and $\mathrm{MgO}$, deposited in the same experimental conditions, a clear increase of the droplets' density was observed. They tend to accumulate in a majority in clusters of particles, with only a few isolated particles being identified. $\mathrm{BHA}$ doped with $\mathrm{MgO}$ (BHA:MgO) displayed the largest area of film surface covered by particle clusters. Apparently, the mean size of the droplets was very similar between undoped and doped materials.

In the case of BHA doped with $\mathrm{Li}_{2} \mathrm{CO}_{3}$ and $\mathrm{Li}_{3} \mathrm{PO}_{4}$ structures (further denoted as $\mathrm{BHA}: \mathrm{LiC}$ and BHA:LiP) [60], the films' surface was flat, with isolated round droplets, sputtered on the surface. Most droplets were more than half embedded in the film mass, which is an indicative for their high velocity at the moment of impact with the surface. The droplets' number quantification was performed on four randomly chosen SEM fields and the obtained values were of $(2.2 \pm 0.2) \times 10^{4}$ particulates $/ \mathrm{mm}^{2}$ (for BHA), $(2.8 \pm 0.2) \times 10^{4}$ particulates $/ \mathrm{mm}^{2}$ (for BHA:LiC) and $(1.5 \pm 0.1) \times 10^{4}$ particulates $/ \mathrm{mm}^{2}$ (for BHA:LiP) [60].

From the cross-sectional SEM images, thicknesses of $\sim 8.5, \sim 7.2$, and $\sim 6 \mu \mathrm{m}$, respectively, were inferred for BHA, BHA:LiC, and BHA:LiP coatings [60].

Comparative SEM micrographies showing different surface morphologies, which correspond to titanium and various types of BioHA coatings synthesized by PLD, using the same deposition conditions, are presented in Figure 3. 


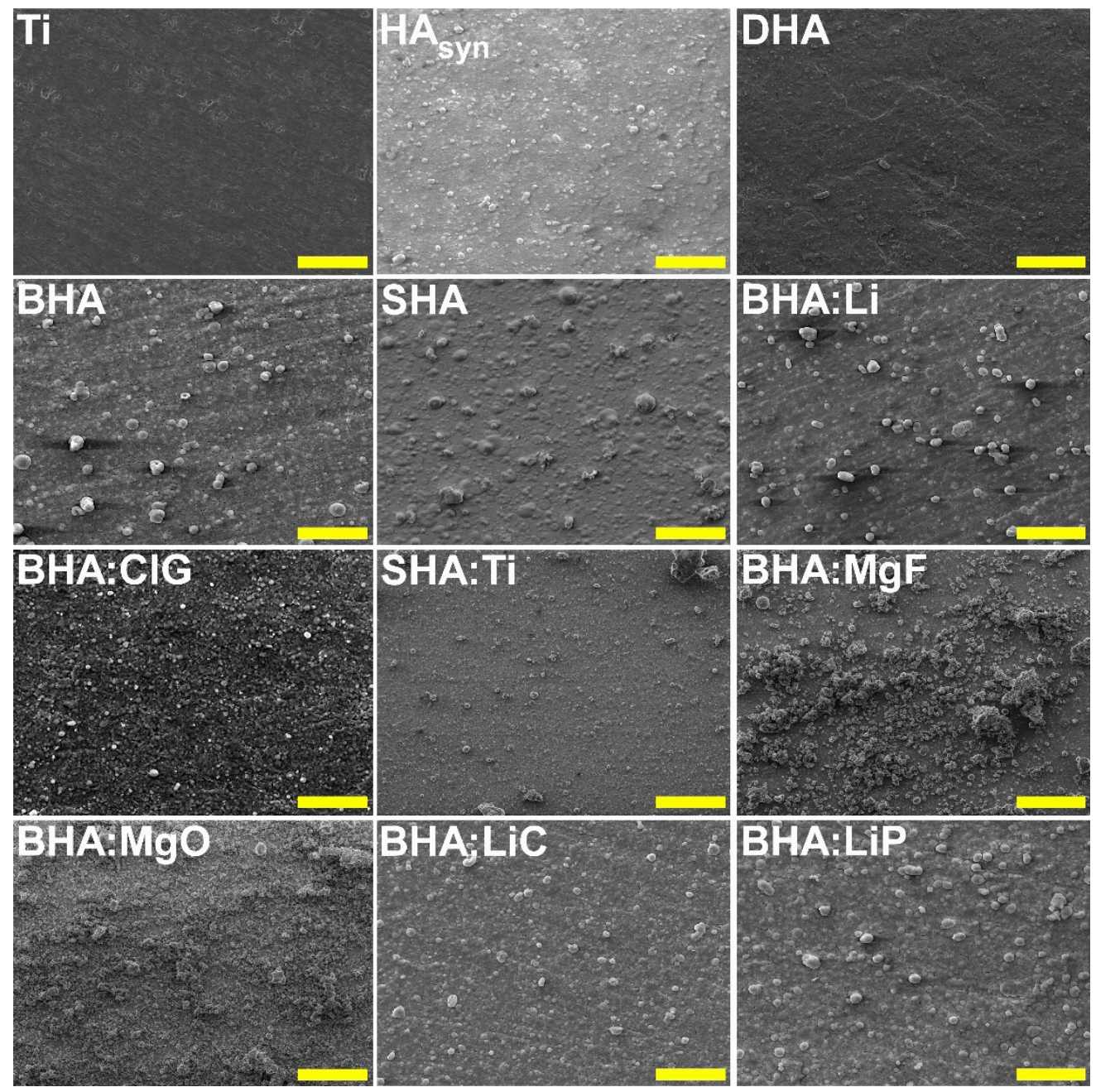

Figure 3. SEM micrographies corresponding to the surfaces of titanium and different types of BioHA coatings synthesized by PLD. Magnification bar: $50 \mu \mathrm{m}$.

Thickness of the PLD synthesized coatings can play an important role on their morphology, especially in the case of rough substrates. In Reference [89], films deposited in a water-vapor atmosphere onto Ti substrates were significantly thinner as compared to the ones deposited in vacuum. The calculated deposition rates were $3.5 \mathrm{~nm} / \mathrm{min}$ for depositions conducted in water vapors, and $18.1 \mathrm{~nm} / \mathrm{min}$ for depositions performed in vacuum. Therefore, films deposited in water vapors were thin and mimicked the Ti surface morphology. For deposition times under $30 \mathrm{~min}$, surface features were not evident. For deposition times between 30 and $120 \mathrm{~min}$, surface features became prominent. Aggregates of globular shape became visible at magnifications of $5000 \times$, while at 20,000x, the droplets appeared to be made of elongated acicular crystalline structures of $<1 \mu \mathrm{m}$ in length.

In general, the EDS quantitative measurements are performed during SEM investigations to determine the elemental distribution in the synthesized films and to estimate the $\mathrm{Ca} / \mathrm{P}$ ratio.

A cross-sectional SEM image and its corresponding EDS spectra in the case of a BHA:CIG coating synthesized by PLD is presented in Figure 4. A compact structure of the coating can be observed. Moreover, the presence of trace elements ( $\mathrm{Na}, \mathrm{Mg}$, $\mathrm{Si}$, etc.) is also emphasized. A quasi-stoichiometric target-to-substrate transfer is reported in which the inferred $\mathrm{Ca} / \mathrm{P}$ molar ratio is $\sim 1.70$. This value is typical to natural bone due to multiple doping with trace elements and functional groups. 


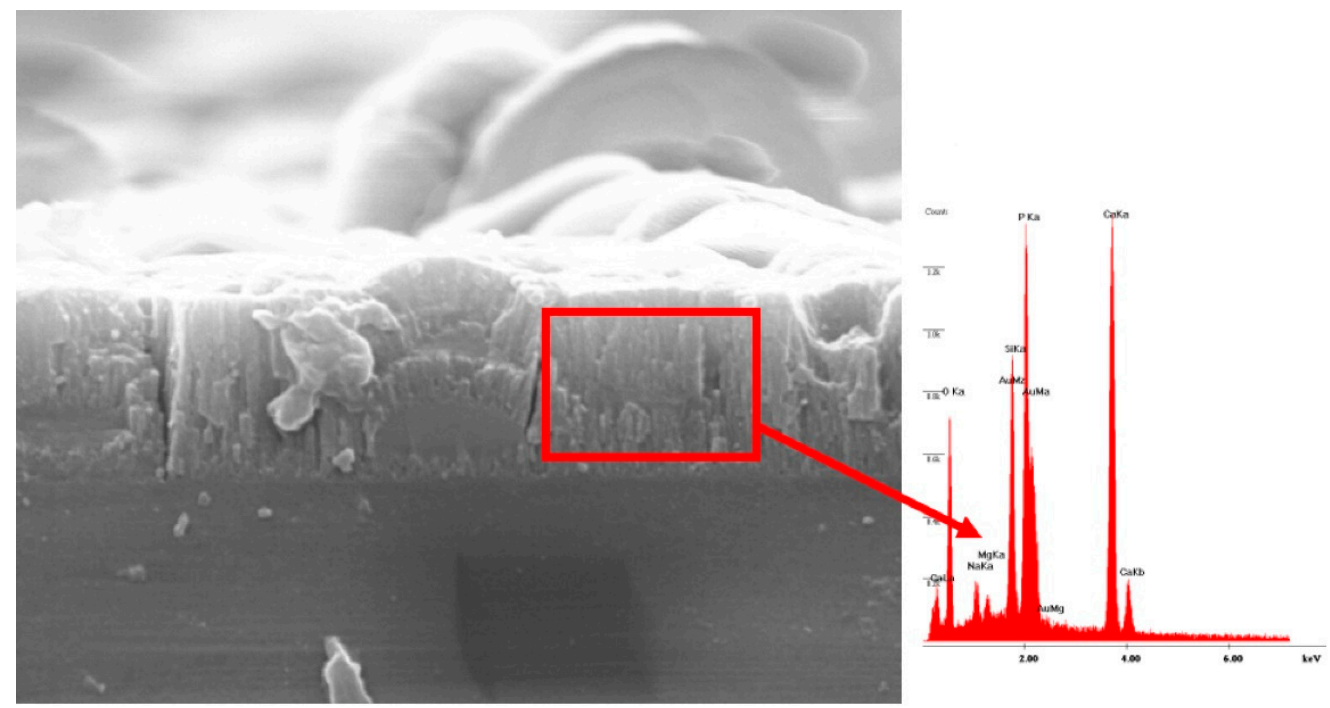

Figure 4. Cross-sectional SEM image and the corresponding EDS spectrum of a bovine hydroxyapatite doped with commercial inert glass coating synthesized by PLD.

\subsection{Structural Investigations}

GIXRD patterns of post-deposition treated BioHA coatings synthesized by PLD should display the characteristic peaks of HA [hexagonal, P63/m (176) space group, ICDD: 00-009-0432] [25]. It is quite possible that the GIXRD patterns contain, besides the HA peaks, some pronounced humps (centered at $2 \theta \approx 30^{\circ}$ ), which are proof of an amorphous phase in the deposited films. Duta et al. [25] reported for SHA films deposited by PLD a crystallinity degree of $\sim 35 \%$. The starting powders for PLD targets displayed in the XRD patterns some peaks that could be associated to $\mathrm{MgCO}_{3}$ (ICDD: 01-086-2345) and $\mathrm{CaMg}_{2}$ (ICDD: 00-013-0450) phases. However, after the deposition, these crystalline peaks were not present in the GIXRD patterns [25].

Some typical XRD patterns of $\mathrm{HA}_{\text {syn }}$ and BioHA coatings undoped or doped with $\mathrm{Li}_{2} \mathrm{O}$ (further denoted as BHA:Li) synthesized by PLD are presented comparatively in Figure 5. One can observe that the most intensive peaks of the patterns in Figure 5 appertain to the Ti peaks of the substrate (ICDD: 44-1294). The fabricated coatings consisted of an HA phase with different degrees of crystallinity, as observed from the diffracted intensity variation and the mean crystallite sizes estimated from the FWHM of (002) and (300) XRD lines [53]. It is visible in Figure 5 that a more pronounced crystallinity corresponds to BHA:Li films. In addition, several weak lines were also identified whose origin might be due to a small percent of oxygen-deficient titanium oxides. Their formation might be due to the substrate oxidation during the post-deposition treatments [53]. 


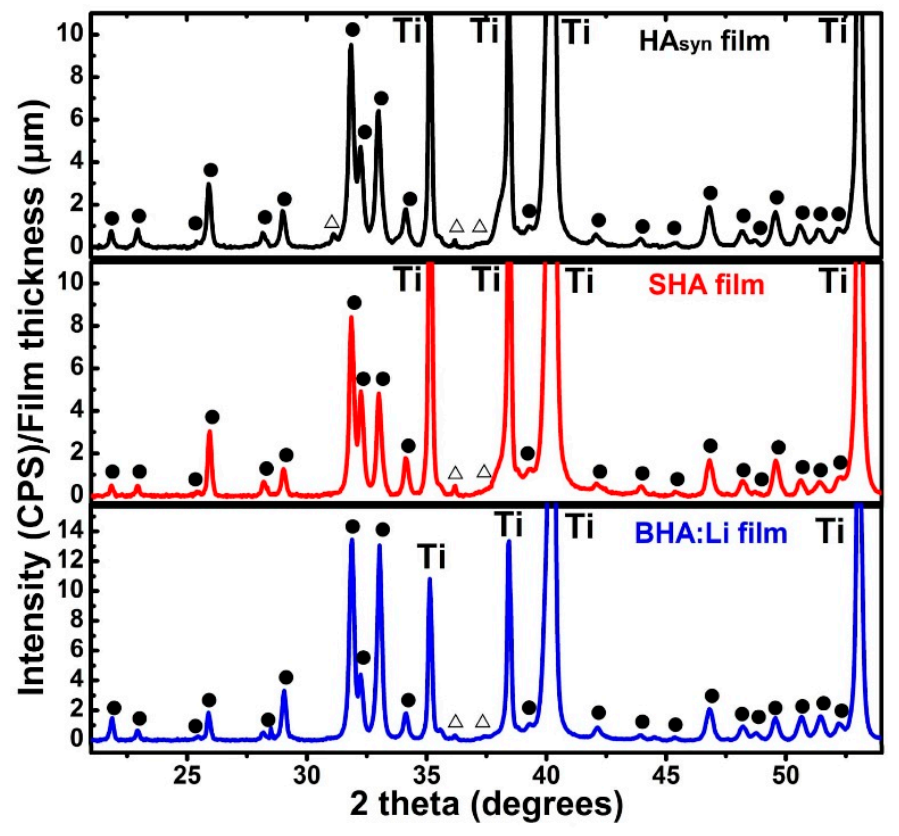

Figure 5. Comparative XRD patterns of synthetic and BioHA coatings synthesized by PLD onto titanium substrates $\left(\bullet, \mathrm{HA} ; \Delta, \mathrm{TiO}\right.$, and $\mathrm{Ti}_{2} \mathrm{O}$ sub-oxides). Reprinted from Reference [53], with permission from Elsevier.

Another way to identify BioHA is by means of characteristic functional groups that can be detected by FTIR. Besides the characteristic HA bands of $v 3$ asymmetric stretching mode of $\left(\mathrm{PO}_{4}\right)^{3-}$ groups (1010-982, 1063-1023, and 1091-1090 $\mathrm{cm}^{-1}$, respectively), the $v 1$ symmetric stretching mode of $\left(\mathrm{PO}_{4}\right)^{3-}$ groups (961-945 cm $\left.\mathrm{cm}^{-1}\right), v 4$ bending mode of $\left(\mathrm{PO}_{4}\right)^{3-}$ groups (558-553 and 600-594 $\mathrm{cm}^{-1}$, respectively), and the peak at $\sim 630 \mathrm{~cm}^{-1}$ characteristic to $(\mathrm{OH})^{-}$groups, in the case of BioHA, which is a band centered at $874-870 \mathrm{~cm}^{-1}$, could be present in the spectra, assigned to $\left(\mathrm{HPO}_{4}\right)^{2-}$ groups.

In the case of BHA targets and films, Duta et al. [53] identified small traces of hydrogen phosphorus fluoride hydrate (ICDD:77-0136) and brushite in the PLD targets [ $\left.\mathrm{CaPO}_{3}(\mathrm{OH}) \cdot 2 \mathrm{H}_{2} \mathrm{O}, \mathrm{ICDD}: 11-0293\right]$. These traces were not present in the films obtained from irradiating these targets. Both targets and films displayed low amounts of fluorine besides the main HA phase. Popescu et al. [60] identified in BHA targets and films only FTIR bands corresponding to carbonate groups besides the characteristic orthophosphate bands of HA.

In the case of HA obtained from shark teeth, Hidalgo-Robatto et al. [89] reported on depositions conducted in water vapors. Depending on the pressure, different degrees of crystallinity were obtained. Under 0.25 mbar, spectra revealed a singular broad peak centered at $\sim 31^{\circ}$, while, for a pressure of 0.45 mbar, the characteristic peaks for apatites located at $29.4,32.1$, and $33.4^{\circ}$, respectively, were present. In the FTIR spectra, besides the characteristic groups of CaPs, a peak associated with carbonate groups was present at $870 \mathrm{~cm}^{-1}$. Depending on the deposition conditions, the importance of this peak varied. As the vapor pressure increased, the intensity of carbonate bands also increased. The $\mathrm{CO}_{3}{ }^{2-} / \mathrm{PO}_{4}{ }^{3-}$ ratio was $30 \%$ higher in the BioHA coating deposited at $0.45 \mathrm{mbar}_{2} \mathrm{O}$ vapors as compared to the case of depositions conducted without water vapors. F1s transition peaks were also shown by XPS in the PLD targets and in deposited films. Based on FTIR, XRD, and XPS results, one could conclude that films deposited by PLD from shark-derived HA contained a hydrated and fluorinated carbonated HA.

\subsection{Bonding Strength Tests}

The bonding strength at the bio-functional coating-substrate interface is considered a critical parameter for the fabrication, successful implantation, and long-term stability of implant-type structures, since it governs both the initial stability and long-term functioning of the medical devices $[16,146]$. 
The bounding strength values inferred for Ti, BHA, and doped BHA coatings synthesized by PLD are presented in Figure 6. The raw data of the obtained results reported in References $[25,53,54,60,80]$ were plotted together for comparison reasons only.

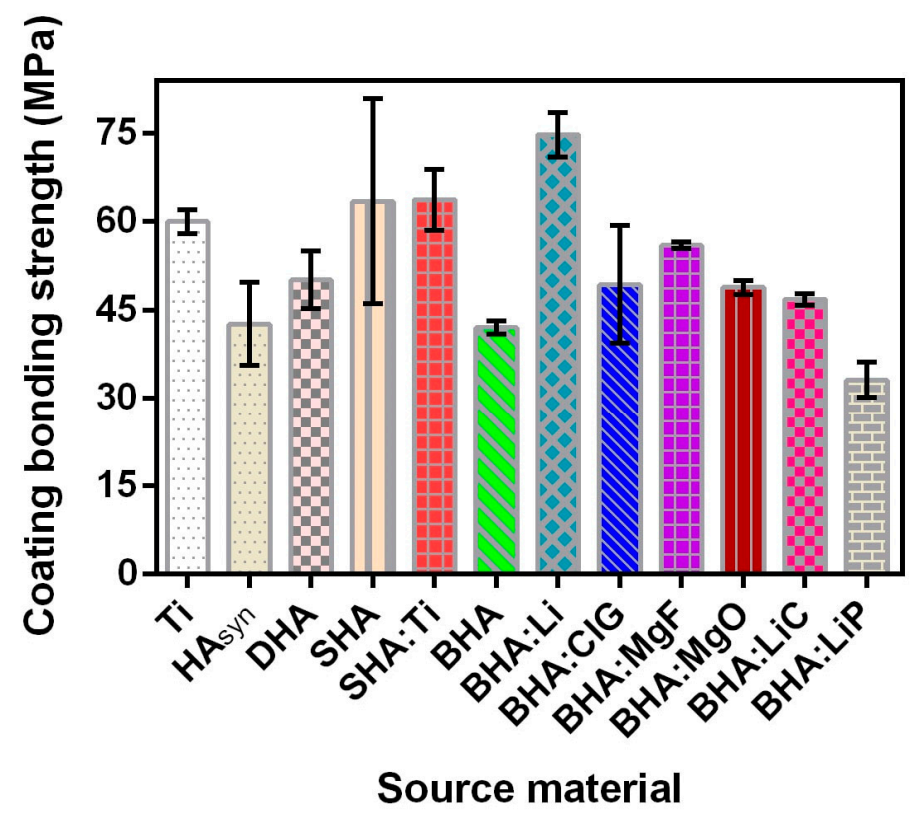

Figure 6. Bonding strength values in the case of titanium and different BioHA coatings synthesized by PLD using the same experimental conditions.

First, in order to verify the quality of the bonding adhesive, control tests are carried out on bare Ti substrates. The adherence values determined at the stainless-steel dolly/Ti substrate interface were of $\sim 60 \mathrm{MPa}$. We note that this value is in accordance with the specifications provided by the manufacturer [147].

Duta et al. [53] recorded for the case of $\mathrm{HA}_{\text {syn }}$ coatings, adherence values generally similar to the ones reported in literature for HA films synthesized by PLD $[148,149]$. Significantly higher values were measured in the case of SHA and BHA:Li coatings. The decreased value of adherence registered for the BHA:CIG structure was attributed to the intrinsic friability of the glassy doping phase under mechanical stress [53].

Duta et al. [25] performed comparative pull-out adherence tests between SHA and SHA:Ti structures. The values recorded for SHA coatings were of $\sim 55 \mathrm{MPa}$, while, for the doped ones, the values were of $\sim 64 \mathrm{MPa}$. The increase in bonding strength of SHA:Ti coatings was due to the presence of the Ti-Ca segregation at the interface with the substrate. One notes that, during post-deposition annealing treatments, atomic inter-diffusion processes are known to take place at the coating-Ti substrate interface [150-152]. In general, this leads to the strengthening of the films' adherence by smoothing the interface between the two different materials. Therefore, the existence at the interfacial region of a segregated Ti-Ca inter-layer could accommodate an easier and more homogeneous inter-diffusion during the progress of the heat-treatments [25].

Mihailescu et al. [54] investigated the bonding strength for BHA and doped BHA structures. Compared to $\mathrm{BHA}$ coatings, the addition of $\mathrm{MgF}_{2}$ and $\mathrm{MgO}$ seemed to result in an improvement of the films' adherence to the Ti substrate with mean bonding strength values of $\sim 49$ and $\sim 56 \mathrm{MPa}$, respectively, being measured [54].

Popescu et al. [60] reported on similar coating adherence values of (42-46) MPa, in the case of BHA and BHA:LiC coatings. These values are in agreement with the ones inferred by Duta et al. [80]. A decrease of the bonding strength down to $33 \mathrm{MPa}$ was recorded in the case of BHA:LiP structures, which was attributed to the existence of a larger content of the amorphous counterpart [60]. 
It is important to emphasize that the bonding strength response measured for all coatings synthesized by PLD (Figure 6) was superior to the minimum mandatory value of $15 \mathrm{MPa}$ imposed by international standard 13779-2 [153] in the case of implant-type coatings used for load-bearing applications.

\subsection{In vitro Biological Observations}

\subsubsection{Bioactivity Effect}

The most common method to qualitatively assess BioHA coatings' biocompatibility and cells' proliferation is the MTS assay, while cells' toxicity can be determined by using a lactate dehydrogenase (LDH) activity test. The MTS assay is based on the use of a tetrazolium compound (3-(4,5-dimethylthiazol-2-yl)-5-(3-carboxymethoxyphenyl)-2-(4-sulfophenyl)-2H-tetrazolium, inner salt - MTS) that is chemically reduced by viable cells into formazan, which is soluble in tissue culture medium. Since the production of formazan is proportional to the number of living cells, the intensity of the produced color can be used as an indicator of cell proliferation.

LDH (or LD) is an enzyme involved in energy production that is found in almost all of the body's cells. Elevated levels of LD usually indicate some type of cell damage. LD levels will typically peak as the cellular destruction begins. Thus, if a substrate is cytotoxic, the detected LD levels will be high. In Reference [25], tests were conducted according to the ISO standard 10993-5 [154].

In literature, the biocompatibility of synthesized coatings was assessed by the MTS tests, by applying different protocols. In this respect, human mesenchymal stem cells (hMSC) were seeded on $\mathrm{Ti}$ and various BioHA surfaces and the obtained results are plotted in Figure $7 \mathrm{a}, \mathrm{b}$ and reported in References [25,60].
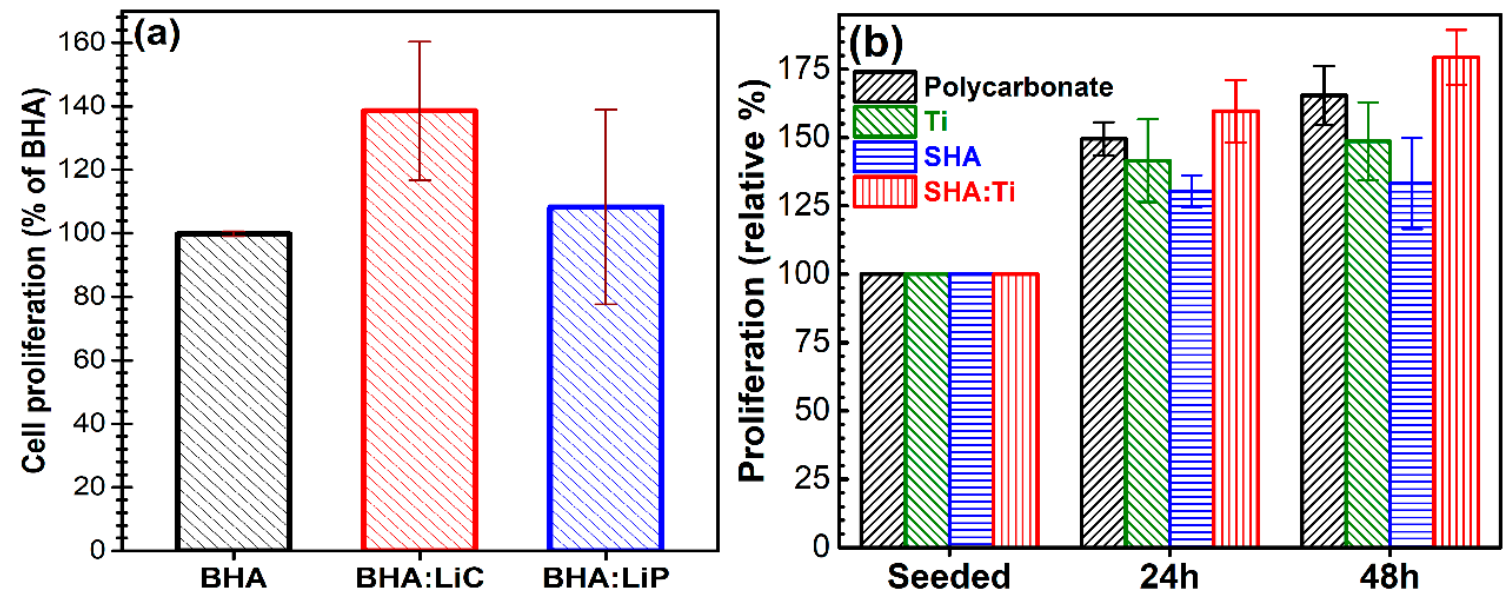

Figure 7. Proliferation of human mesenchymal stem cells assessed by MTS assay in the case of (a) bovine hydroxyapatite (BHA) and doped BHA coatings and (b) Ti, sheep hydroxyapatite (SHA), and doped SHA coatings synthesized by PLD. Reprinted from References [25,60], with permission from Elsevier. Slight modifications of the acronyms from the original figures were done to be in agreement with the sample codes used in this review.

In Figure 7a, one can observe that the cells' proliferation was better in the case of doped BHA coatings with respect to undoped ones. The proliferation increase was demonstrated to be in a direct relation with the augmentation of the polar component of the surface-free energy. Therefore, the beneficial effect of $\mathrm{Li}_{2} \mathrm{CO}_{3}$-doping could be emphasized [60].

After 24 and $48 \mathrm{~h}$, the proliferation capacity of cells grown on the surface of SHA and SHA:Ti coatings was improved as compared to Ti surfaces for the same time intervals (Figure 7b). In addition, cell death at $24 \mathrm{~h}$ of growth was tested by using the LDH method [25]. 
Lithium is a trace metal in organisms. In pharmacy, it is used in composition of various drugs for the treatment of bipolar affective disorder and depression [155]. Lithium was also administered in drugs for treating osteoporosis in the last 20 years $[156,157]$ due to its proven ability to enhance osteogenesis [158]. Despite its proven efficacy [159], there are reports when lithium administration determined side effects such as thirst and excessive urination, nausea, diarrhea, tremor, weight gain, sexual dysfunction, dermatological effects, and long-term effects on the thyroid gland, kidneys, and parathyroid glands [160]. However, recent studies challenge this negative perception of lithium administration, stating that intoxication occurs only when the concentration is higher than $1.5 \mathrm{mmol} / \mathrm{L}$, and its main adverse effects can be properly monitored and managed [11,161-163].

Hidalgo-Robatto et al. [89] tested BioHA coatings (obtained from shark teeth) synthesized by PLD using a pre-osteoblastic cell line MC3T3-E1. The BioHA was compared to synthetic HA and a control of tissue culture polystyrene. Cell morphology was similar in the case of synthetic HA and BioHA. Both coatings were able to promote healthy morphology on the cells. MC3T3-E1 cells made contact with neighboring cells and covered the entire surface of their respective coatings. The MTT assay showed after seven days from seeding, an intense proliferation of cells on the biological apatite coatings, which is significantly higher than the proliferation on the synthetic HA coatings or the control by the MTS assay. After 21 days, all tested materials had higher values of cell proliferation than on day 7 and displayed similar absorbance values. Alkaline phosphatase (ALP) activity was tested as a measure of osteoblastic activity and bone formation. Statistically significant higher ALP activity was quantified on the BioHA coatings compared to both the synthetic HA and TCP, which presented lower values in the same range. After 21 days of incubation, both types of apatite coatings apparently manifested higher levels of ALP activity as compared to TCP values. Overall, BioHA seemed to accelerate osteogenic activity as compared to synthetic HA due to its fluoride content and its trace elements such as $\mathrm{Na}$ and $\mathrm{Mg}$.

Doping of BioHA with various elements can drastically increase the cellular response toward PLD synthesized coatings. In such a study, the surfaces of medical-grade Ti, SHA, and SHA:Ti coatings (the precursor material for PLD targets was a mix of SHA powder and $1.5 \mathrm{wt} . \%$ Ti powder) were seeded with human mesenchymal stem cells (hMSC) [25]. On all types of samples, cells displayed the same typical morphology: small dimensions, well-spread, and having a polygonal shape. They have established liaisons with neighbouring cells by thin cellular extensions. The lowest proliferation value was reached for the SHA coatings, with respect to both SHA:Ti ones and controls (bare Ti and polycarbonate) [25]. The experiments also showed an important cell number growth (of $\sim 60 \%$ ) in the case of SHA:Ti coated samples. The proliferation increase of SHA:Ti vs. SHA was found statistically significant $(\mathrm{p}<0.05)$. The LDH results showed that both SHA and SHA:Ti coatings fostered a good cells' cytocompatibility. However, the amount of cells that underwent apoptosis and death was lower in the case of the polycarbonate control and SHA:Ti coatings. SHA structures presented almost double cell apoptosis death as compared to SHA:Ti ones. The dead cells' index (percent of dead cells from the total number of cells) was lower than $4.5 \%$ for all cases, which constitutes another proof of the good cytocompatibility of the PLD coatings. The beneficial effect of Ti doping in HA has not been yet completely elucidated. Duta et al. [25] advanced its lower degree of crystallinity as a possible explanation for the superior biocompatibility of SHA:Ti, which generated the premises for a better interaction with the organic component of the mesenchymal cell culture media. $\mathrm{Ca}^{2+}$ ions released by dissolution may act as binders for organic moieties from culture media with roles in the healthy development of cells. A similar interpretation of enhanced protein binding by HA:Ti has been advanced by Kandori et al. [164] and Wei et al. [165], respectively.

In Reference [60], the influence of lithium doping of BHA on the biological response of the same type of cells was tested. The cells were stained with calcein/EthD-1 in order to evaluate the viable ones and the morphology of hMSC was observed three days after seeding on the surface of undoped and doped coatings. BHA:LiC and BHA:LiP samples produced a decrease in cell spreading without significantly modifying cell viability. Cells were adherent on the tested materials and exhibited typical 
fibroblast-like characteristics, with dendrites and prominent nuclei. There was no visible difference between lithium-doped BHA coatings and control materials (bare Ti and undoped BHA samples), as shown in Figure 8.

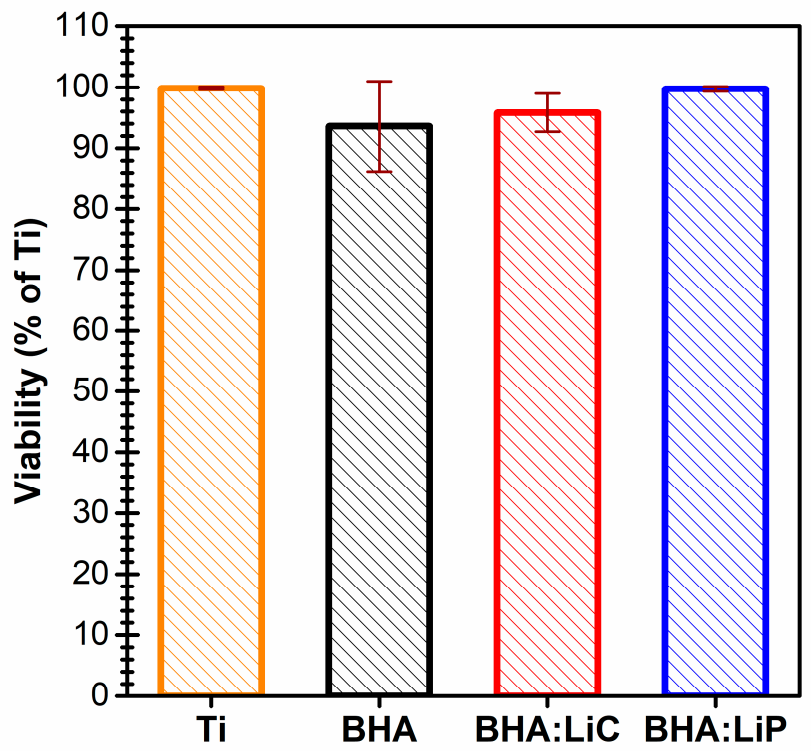

Figure 8. Cellular viability of human mesenchymal stem cells after $72 \mathrm{~h}$ of growth on the surface of Ti, bovine hydroxyapatite (BHA), and doped BHA coatings synthesized by PLD using the same experimental conditions. Reprinted from Reference [60], with permission from Elsevier. Slight modifications of the acronyms from the original figure were done for uniformization with the sample codes used in this review.

The in vitro cellular viability of hMSC grown for $72 \mathrm{~h}$ on Ti, BHA, and doped BHA coatings was assessed using the calcein AM/EthD-1 [60] method and the results are presented in Figure 8.

Based on relative intensity of calcein and EthD-1 signals on resulting scatter-grams, positive from negative cell populations could be distinguished. Compared to BHA samples, lithium-doped and $\mathrm{MgF}_{2}$-doped surfaces led to a slight improved growth of hMSC cells, whilst, for BHA:CIG and BHA:MgO surfaces, a reduced cellular viability was inferred (Figure 8).

The high biocompatibility of BHA:LiC coatings was assumed to be favored by the highest wettability and overall surface energy, as well as by an augmented contribution of the polar component of the surface energy. Other studies report in favor of this hypothesis that, in order to enhance the cellular response (including here adhesion, spreading, and cytoskeletal organization), an optimal window for the contact angle in the range of $60^{\circ}$ to $80^{\circ}$ between surface and water molecules should exist [166-168]. In this case, the cell proliferation results are in good agreement with this rationale, with the best results being obtained for coatings to elicit a water contact angle of $\sim 72^{\circ}$ and the highest polar component.

Dos Santos et al. [169] and Redey et al. [170] reported that the higher polar component of carbonated HA and natural calcium carbonated surfaces induced an increased osteoblast and osteoclast adhesion, respectively. Furthermore, Zhao et al. [171] indicated that a higher surface free energy is connected with the increased production of bone ALP and osteocalcin, in the case of MG63 osteoblastic cells grown on hydroxylated Ti surfaces.

\subsubsection{Antibacterial Effect}

Mihailescu et al. [54] tested BHA and BHA:MgF or BHA:MgO against gram-positive Micrococcus $s p$. and gram-negative Enterobacter sp. for $72 \mathrm{~h}$. The BHA coatings and Ti substrate used as controls had no antibacterial effect. When BHA was doped with $\mathrm{MgF}_{2}$, and pulsed laser deposited on a substrate, it 
exhibited a slight anti-biofilm activity ( 1 log reduction of viable cell counts as compared to bare Ti) toward Enterobacter sp. The highest anti-biofilm activity was observed for the BHA:MgO coatings, which inhibited the Enterobacter sp. biofilm in all development stages, Micrococcus sp. biofilm at 24 and $72 \mathrm{~h}$, and C. albicans biofilm at $48 \mathrm{~h}$.

In Reference [172], it was shown that $\mathrm{MgO}$ exhibits stronger bactericidal activity as compared to $\mathrm{TiO}_{2}$. Two hypotheses explaining the decrease of the number of biofilm-embedded cells could be considered, i.e. (i) the surface coatings prevent the microbial/bacteria adhesion and (ii) the coatings exhibit a microbicidal activity, which kills the cells before or after contact with the coated surfaces. The second hypothesis is supported by the results of the minimal inhibitory concentration assay showing an increased microbicidal activity of $\mathrm{BHA}: \mathrm{MgO}$ and BHA:MgF coatings as compared to BHA against the tested strains. No cytotoxic activity of deposited coatings against human cells was revealed during tests on Hep2 cells. It has been reported in literature that pure $\mathrm{Mg}$ is highly effective against Staphylococcus aureus (S. aureus) [173]. Numerous studies tested the antibacterial efficiency of $\mathrm{MgO}$ against bacteria. Sawai et al. [174] demonstrated the efficiency of MgO powders against S. aureus and Escherichia coli, while Gayathri et al. [175] created a doped HA containing Mg in the form of nanoparticles that had antibacterial efficiency, but also insecticide action, which killed the larvae of three mosquito species. Photoluminescence studies conducted by Sawai et al. [174] showed that $\mathrm{MgO}$ slurries generate active oxygen species such as $\mathrm{O}^{2-}$ and this seems to be the most probable cause for bacterial apoptosis. These oxygen species form in wet media hydroxyl radicals and hydrogen peroxide. Hydroxyl radical is the most reactive oxygen radical, able to interact with almost every type of molecule of the living cells of bacteria and fungi, which causes irreversible damage to cellular components and, eventually, apoptosis [176].

$\mathrm{Mg}$ is not toxic for the human organism in a dose of 200 to $400 \mathrm{mg}$ per day. The Food and Nutrition Board of the Institute of Medicine in the United States has set an upper tolerable limit of $350 \mathrm{mg}$ per day for supplemental magnesium. In larger doses, it can induce nausea and vomiting, muscle pain and weakness, confusion, and cardiac arrhythmias [177].

BHA and BHA doped with lithium compounds such as carbonate and phosphate (i.e., BHA:LiC or BHA:LiP coatings) proved antibacterial and antifungal activity against $S$. aureus and C. albicans strains [11], which was an unexpected discovery. After $24 \mathrm{~h}$, all tested coatings manifested inhibitory activity for S. aureus colonies. After 48 and $72 \mathrm{~h}$ from inoculation, the antibacterial effect was much more visible. Therefore, a drastic decrease in the number of $\mathrm{CFU} / \mathrm{mL}$ of 2 to 4 logs at these two-time intervals was recorded (Figure 9). 


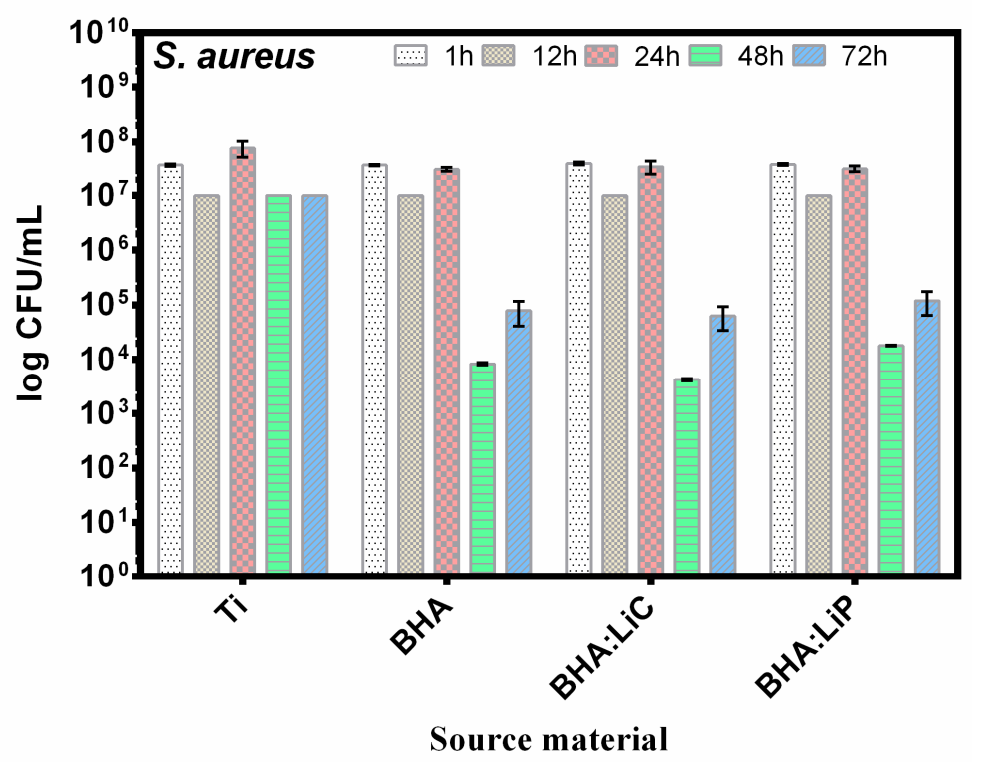

Figure 9. Graphic representation of the logarithmic values of $S$. aureus biofilm cells developed on the surfaces of Ti, bovine hydroxyapatite (BHA), and doped BHA coatings, at different time intervals (1-72 h) [11]. Slight modifications of the acronyms from the original figure were done for uniformization with the sample codes used in this review.

Representative SEM images of S. aureus biofilm developed on the surface of Ti and BHA:Li structures are given in Figure 10, at a magnification of 10,000x. One can observe that the density of $S$. aureus cells was significantly more reduced on BHA:Li surfaces as compared to Ti ones, which is in good agreement with the quantitative results presented in Figure 9.
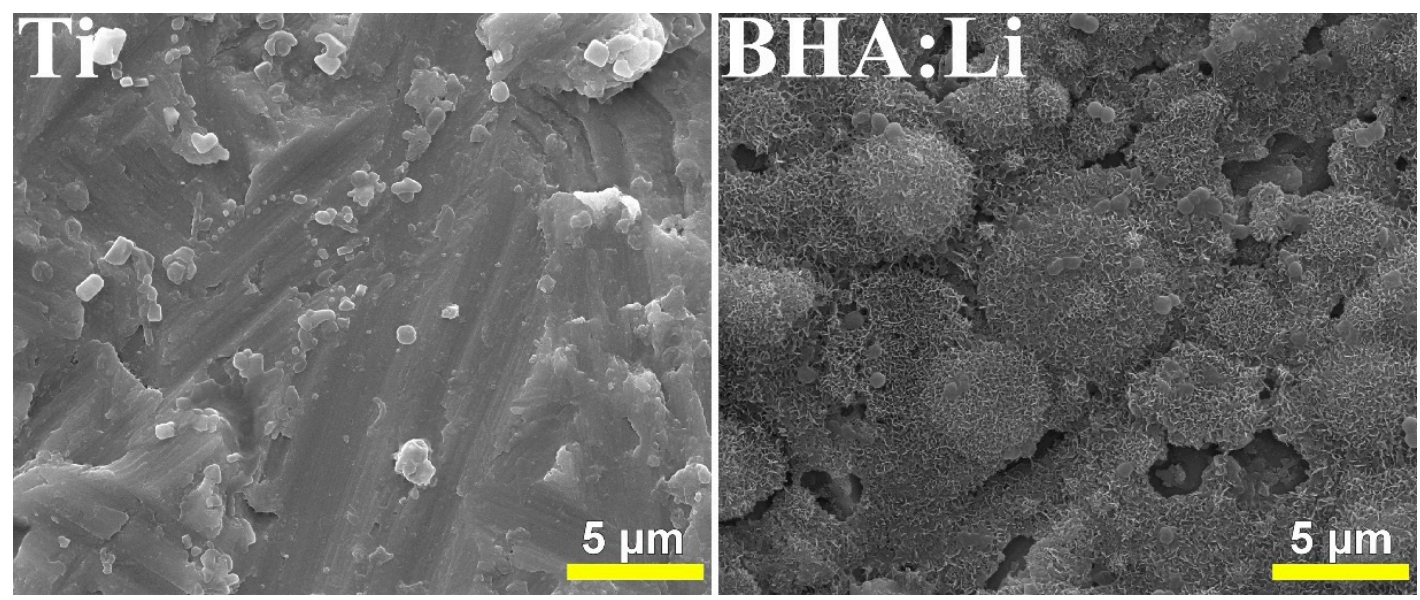

Figure 10. SEM images corresponding to $S$. aureus biofilm after $72 \mathrm{~h}$ of development on the surfaces of $\mathrm{Ti}$ and bovine hydroxyapatite doped with $\mathrm{Li}_{2} \mathrm{O}$ coatings.

BHA:LiC coatings exhibited a slightly increased antimicrobial activity against $S$. aureus biofilm, as compared to BHA and BHA:LiP ones. In the case of $C$. albicans, the antifungal activity started to be pronounced after $12 \mathrm{~h}$ of incubation and with a drastic decrease of the fungal biofilm after 48 and $72 \mathrm{~h}$, respectively (Figure 11). 


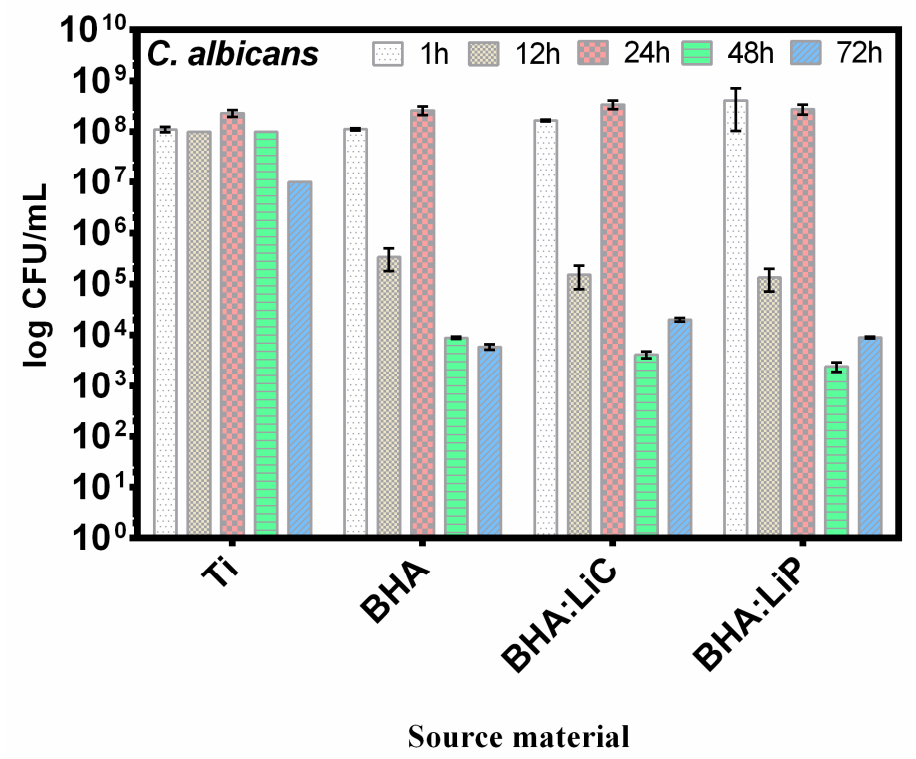

Figure 11. Graphic representation of the logarithmic values of $C$. albicans biofilm cells developed on the surfaces of Ti, bovine hydroxyapatite (BHA), and doped BHA coatings, at different time intervals (1-72 h) [11]. Slight modifications of the acronyms from the original figure were done for uniformization with the sample codes used in this review.

Again, the order of efficiency in reducing colonies was BHA:LiC > BHA:LiP > BHA. SEM images revealed that, when grown on the surface of Ti, C. albicans produced biofilms, with interconnected cells through filaments, while, when seeded on the surface of the synthesized BHA or doped BHA coatings, the cells were ovoid and adhered in isolated unicellular forms, with completely absent filaments (Figure 12).
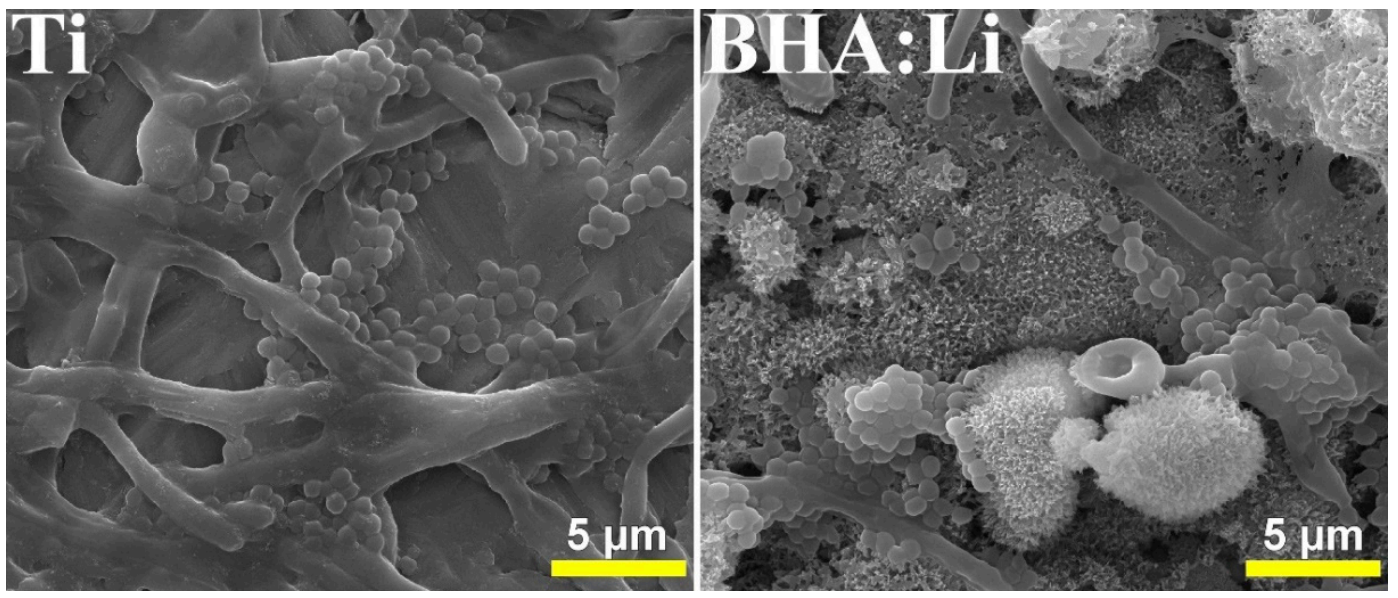

Figure 12. SEM images corresponding to $C$. albicans biofilm after $72 \mathrm{~h}$ of development on the surfaces of $\mathrm{Ti}$ and bovine hydroxyapatite doped with $\mathrm{Li}_{2} \mathrm{O}$ coatings.

Representative SEM images of C. albicans biofilm developed on the surfaces of Ti and BHA:Li structures are given in Figure 12, at a magnification of 10,000x. While bare Ti samples were completely covered by a continuous layer of cells, the number of yeast cells developed on the surface of BHA:Li coatings was significantly decreased. They adhered exclusively in isolated, unicellular form, without interconnecting filaments. Duta et al. [11] assessed the antibacterial and antifungal activity of BioHA coatings to one of the following factors: (i) difference in polarity between negative-coated surfaces (associated with the presence of hydroxyl hydrophilic functional groups) and S. aureus/C. 
albicans biofilms matrix, which is also negatively charged, due to its main component, represented by self-produced exopolysaccharides, (ii) coatings will facilitate the formation of a highly alkaline medium, which consequently leads to the destruction of lipids that are the main component of microbial cell membrane, or (iii) the smooth surfaces of the films, which reduce the contact area between material surface and bacterial cells, or (iv) metal accumulation inside bacterial cells, followed by the cellular wall disruption, and, eventually, cellular lysis.

\subsection{In Vivo Tests}

In vitro tests were demonstrated to play a key role in the biological assessment of biomaterials by offering in-sight information on their possible behavior in a biological environment. On the other hand, to understand the complex processes that might occur in a living system and to provide accurate data to completely validate the performances of a given biomaterial designed for clinical trials, in vivo tests are extremely important and should, therefore, follow in vitro ones.

In the literature, there are many in vivo reports on CaPs, but, to the best of our knowledge, there are few works only on HA coatings synthesized by PLD, and, unfortunately, no studies at all on BioHA coatings synthesized by PLD. However, the authors of this review are confident that future in vivo studies of BioHA coatings should deliver interesting results, since BioHA materials proved many times to possess important advantages over synthetic HA. In the following paragraphs, a selection of the papers dealing with PLD of synthetic HA will be considered and the obtained results will be reviewed.

The main purpose of $\mathrm{CaP}$ coatings is to stimulate and accelerate new bone formation around an implant [178], and most of the reported research studies revealed positive and favorable effects in this direction [179]. In general, the spectrum of animals used for testing CaP coatings synthesized by PLD is reduced, and this includes rats, rabbits, mini-pigs, dogs, goats, or sheep [14]. The advantages and disadvantages of different animal models used were discussed in Reference [139].

Chen et al. [180] synthesized using PLD fluoridated synthetic HA (HA:F) structures onto Ti implants and inserted them into rat femurs. By using microcomputed tomography, histology, and sequential polychromatic fluorescent investigations, their osteo-inductive and osseointegration activity in comparison with that of uncoated Ti implants was assessed. The results of their study demonstrated that HA:F-coated implants were characterized by superior osteogenesis and osseointegration properties (1.5 times more new bone at one week and more than four times more new bone at 4 and 8 weeks, respectively) as compared to bare (uncoated) Ti specimens, which can advance them as viable candidates for future applications in dentistry.

Mroz et al. [181] reported on Mg-doped HA coatings fabricated by PLD onto porous Ti implants, which were introduced in rabbit femoral bones for six months. The evaluation of bone-implant interaction and bone volume in the region of interest were performed. Histopathological investigations showed that all implants integrated well with the surrounding bone with ingrowth of newly formed bone into the pores of the implants. No inflammatory or foreign body reaction were noticed at the implant site. They note that, a significant increase in bone volume for Mg-doped HA implants, as compared to uncoated implants, was detected.

Peraire et al. [182] conducted a comparative study of the biological stability and the osteo-conductivity of HA coatings produced by PLD and plasma spraying. The functionalized grit-blasted titanium rods were implanted in the proximal tibia of mature New Zealand White rabbits. The obtained data suggested superior bone growth (percentage of bone contact) in the case of HA-PLD coatings ( $86 \%)$ as compared to the HA-PS coatings (67\%) or the uncoated grit-blasted titanium $(69 \%)$, after a period of 24 weeks implantation. Taking into consideration these results, the initiation of clinical evaluation of this coating method for medical applications was encouraged.

Mihailescu et al. [183] reported on synthetic HA, $\mathrm{Mn}^{2+}$-doped carbonated HA and octacalcium phosphate (OCP) coatings fabricated by PLD onto Ti implants for insertion in the tibia bones of New Zealand White female rabbits. The bone-implants bonding was assessed by a tensile (pull-out) test. The measured value of the pull-out force was found to be more than double in the case of 
CaP-functionalized Ti implants, as compared to the control (uncoated) ones. In addition, the pull-out force increased by $25 \%$ for the $\mathrm{Mn}^{2+}$-doped carbonated HA and $10 \%$ in OCP-coated implants, in comparison with the synthetic HA-coated implants. Mihailescu et al. concluded that nanostructured $\mathrm{CaP}$ depositions manifested a significant potential for improving the performance of functionalized $\mathrm{Ti}$ implants in bone, and the composition and structure of the CaP coating have a significant influence on their biological effect.

Dostalova et al. [184] functionalized by PLD the surface of Ti6Al4V dental implants with HA coatings. Coated and uncoated implants were inserted into the lower jaw of mini-pigs. The evaluation of implants' osseointegration degree was assessed by polarized and fluorescent light microscopy with computer image processing. The results of the study proved that the osseointegration of the coated layer was superior for HA coatings ( 77.2\%) than the integration of uncoated Ti implants $(\sim 65.2 \%)$. With the owned advantage of delivering an inert and osseoconductive ceramic coating, the same team concluded that the PLD could be a viable method for coating metallic implants.

\section{Conclusions and Perspectives}

When animal-origin calcium phosphates (CaPs) are tackled, pulsed laser deposition (PLD) could be one of the most interesting choices for coating synthesis. If synthetic hydroxyapatite (HA) has a complex molecule with a large number of atoms and functional groups difficult to transfer in form of thin films by physical deposition techniques, natural apatites become even more complicated to transfer because of new functional groups and substitution ions, which further complicate the molecule. PLD is renowned for the ability to transfer stoichiometrically very complex molecules and this advantage should make it one of the premiere candidates for the transfer of such complex materials.

The most common sources for obtaining animal-origin HA for PLD targets are swine, ovine, and bovine teeth or bones. They are immersed in alkali solutions and further calcinated at $\sim 800{ }^{\circ} \mathrm{C}$ to remove the organic parts. The powder resulting after grinding and milling can be pressed into targets or mixed with various doping agents to change mechanical or biocompatibility properties.

Coatings' morphology depends on the thickness, the origin of the natural apatite, and on the doping agents. In general, films are covered by round droplets that originate from the expulsion of the liquid phase during target irradiation. Their number and size can drastically differ depending on the experimental conditions. Usually, films in the range of hundreds of nanometers mimic the substrate morphology (especially if it is rough), with surface features that are not evident. Thickness seems to be dependent on the experimental conditions (number of pulses, laser fluence, and gas pressure), but also on the type of apatite. Studies on coatings synthesized in the same experimental conditions on sheep, cow, and cow-HA and bio-glass revealed different thicknesses for different types of materials.

Structural differences between synthetic HA and animal-origin apatites or between different types of animal origin-apatites cannot be shown by X-ray diffraction only. All these materials display the same crystalline peaks in the diffraction patterns. Differences appear in Fourier transform infrared spectroscopy that contain, in the case of animal-origin $\mathrm{HA}$, bands corresponding to $\left(\mathrm{HPO}_{4}\right)^{2-}$ or $\left(\mathrm{CO}_{3}\right)^{2-}$ groups.

In terms of adherence to the substrate, PLD synthesized coatings from doped or undoped animal-origin HA could easily surpass the mandatory value of $15 \mathrm{MPa}$ of bonding strength established by international standards for biocompatible coatings to be used in implantology.

Biocompatibility of animal-origin HA was consistently being reported as surpassing that of synthetic HA both in cells morphology, cells proliferation, and bioactivity. Moreover, when doped with $\mathrm{Ti}$ or $\mathrm{Li}_{2} \mathrm{CO}_{3}$, the effect was a boost in cell proliferation.

Animal-origin HA could be, therefore, a reliable, promising, safe, and, most importantly, low-cost source for coatings that reach biomimetism. For PLD, the field is still in his incipient development, with numerous possibilities to expand in terms of natural-HA sources, doping agents, or morphology and structural control of the obtained coatings. The transfer from PLD, which is essentially a laboratory technique to an industrial coating technique also belongs to the future. 
Besides their often-increased bioactivity as compared to synthetic HA, BioHA coatings can display antibacterial and antifungal properties, which are not present in the case of synthetic HA. Undoped or BioHA doped with $\mathrm{MgO}$, or carbonates and phosphates of lithium, were active against various microorganisms. Possible explanations for this property could be the presence of dopants, which have antibacterial and antifungal properties by themselves, the smoother surfaces of PLD deposited BioHA films, which reduce the contact area between coating and bacteria, and the metal ions accumulation inside microorganisms followed by the membrane disruption and cell apoptosis.

The authors of this review express their confidence that the future of biomimetic coatings belongs to the natural-origin CaPs source materials and their perfect transfer and delicate tuning in terms of thickness, crystallinity, and functional groups can be optimally studied using PLD as deposition method.

Author Contributions: Conceptualization, L.D. and A.C.P. Methodology, L.D. and A.C.P. Software, L.D. Validation, L.D. and A.C.P. Formal analysis, L.D. and A.C.P. Investigation, L.D. and A.C.P. Resources, L.D. and A.C.P. Data curation, L.D. and A.C.P. Writing-original draft preparation, L.D. and A.C.P. Writing-review and editing, L.D. and A.C.P. Visualization, L.D. and A.C.P. Supervision, L.D. and A.C.P. Project administration, L.D. and A.C.P.

Funding: Two grants from the Ministry of Research and Innovation, CNCS-UEFISCDI, No. PN-III-P1-1.1-PD-2016-1568 (PD 6/2018) and PN-III-P1-1.1-TE-2016-2015 (TE136/2018), within PNCDI III supported this work. The authors acknowledge and thank the partial support from the Core Programme - Contract 16N/2019.

Acknowledgments: The authors acknowledge G.-P. Pelin for the SEM images that were used in this review for exemplification purposes and for the schematic with the PLD experimental set-up, C. Chifiriuc for data on biofilm development on bovine hydroxyapatite doped with $\mathrm{Li}_{2} \mathrm{O}$ coatings, and F.N Oktar for providing animal-origin powders that were used for numerous studies of bioactive coating synthesis.

Conflicts of Interest: The authors declare no conflict of interest.

\section{References}

1. Oladele, I.; Agbabiaka, O.; Olasunkanmi, O. Non-synthetic sources for the development of hydroxyapatite. J. Appl. Biotechnol. Bioeng. 2018, 5, 92-99. [CrossRef]

2. Akram, M.; Ahmed, R.; Shakir, I.; Ibrahim, W.A.W.; Hussain, R. Extracting hydroxyapatite and its precursors from natural resources. J. Mater. Sci. 2014, 49, 1461-1475. [CrossRef]

3. Bigi, A.; Bracci, B.; Cuisinier, F.; Elkaim, R.; Fini, M.; Mayer, I.; Mihailescu, I.N.; Socol, G.; Sturba, L.; Torricelli, P. Human osteoblast response to pulsed laser deposited calcium phosphate coatings. Biomaterials 2005, 26, 2381-2385. [CrossRef]

4. Mihailescu, I.N.; Torricelli, P.; Bigi, A.; Mayer, I.; Iliescu, M.; Werckmann, J.; Socol, G.; Miroiu, F.; Cuisinier, F.; Elkaim, R.; et al. Calcium phosphate thin films synthesized by pulsed laser deposition: Physico-chemical characterization and in vitro cell response. Appl. Surf. Sci. 2005, 248, 344-348. [CrossRef]

5. Dorozhkin, S. History of Calcium Phosphates in Regenerative Medicine. In Advances in Calcium Phosphate Biomaterials; Ben-Nissan, B., Ed.; Springer: Berlin/Heidelberg, Germany, 2014; Volume 2, pp. $435-483$. [CrossRef]

6. Mihailescu, I.N.; Ristoscu, C.; Bigi, A.; Mayer, I. Advanced biomimetic implants based on nanostructured coatings synthesized by pulsed laser technologies. In Laser-Surface Interactions for New Materials Production, Tailoring Structure and Properties; Miotello, A., Ossi, M., Eds.; Springer: Berlin/Heidelberg, Germany, 2010; pp. 235-268. [CrossRef]

7. O'Hare, P.; Meenan, B.J.; Burke, G.A.; Byrne, G.; Dowling, D.; Hunt, J.A. Biological responses to hydroxyapatite surfaces deposited via a co-incident microblasting technique. Biomaterials 2010, 31, 515-522. [CrossRef]

8. Habibovic, P.; Kruyt, M.C.; Juhl, M.V.; Clyens, S.; Martinetti, R.; Dolcini, L.; Theilgaard, N.; van Blitterswijk, C.A. Comparative in vivo study of six hydroxyapatite-based bone graft substitutes. J. Orthop. Res. 2008, 26, 1363-1370. [CrossRef]

9. Marini, E.; Ballanti, P.; Silvestrini, G.; Valdinucci, F.; Bonucci, E. The presence of different growth factors does not influence bone response to hydroxyapatite: preliminary results. J. Orthopaed. Traumatol. 2004, 5, 34-43. [CrossRef]

10. Rabiee, S.; Moztarzadeh, F.; Solati-Hashjin, M. Synthesis and characterization of hydroxyapatite cement. J. Mol. Struct. 2010, 969, 172-175. [CrossRef] 
11. Duta, L.; Chifiriuc, M.C.; Popescu-Pelin, G.; Bleotu, C.; (Pircalabioru) Gradisteanu, G.; Anastasescu, M.; Achim, A.; Popescu, A. Pulsed Laser Deposited Biocompatible Lithium-Doped Hydroxyapatite Coatings with Antimicrobial Activity. Coatings 2019, 9, 54. [CrossRef]

12. Predoi, D.; Iconaru, S.L.; Predoi, M.V. Bioceramic Layers with Antifungal Properties. Coatings 2018, 8, 276. [CrossRef]

13. Prosolov, K.A.; Belyavskaya, O.A.; Linders, J.; Loza, K.; Prymak, O.; Mayer, C.; Rau, J.V.; Epple, M.; Sharkeev, Y.P. Glancing Angle Deposition of Zn-Doped Calcium Phosphate Coatings by RF Magnetron Sputtering. Coatings 2019, 9, 220. [CrossRef]

14. León, B.; Jansen, J.A. Thin Calcium Phosphate Coatings for Medical Implants; Springer: New York, NY, USA, 2009; p. 328. [CrossRef]

15. Rodríguez-Lorenzo, L.M.; Vallet-Regí, M.; Ferreira, J.M.F.; Ginebra, M.P.; Aparicio, C.; Planell, J.A. Hydroxyapatite ceramic bodies with tailored mechanical properties for different applications. J. Biomed. Mater. Res. 2002, 60, 159-166. [CrossRef]

16. Sima, L.E.; Stan, G.E.; Morosanu, C.O.; Melinescu, A.; Ianculescu, A.; Melinte, R.; Neamtu, J.; Petrescu, S.M. Differentiation of mesenchymal stem cells onto highly adherent radio frequency-sputtered carbonated hydroxylapatite thin films. J. Biomed. Mater. Res. 2010, 95, 1203-1214. [CrossRef]

17. Liu, X.; He, D.; Zhou, Z.; Wang, G.; Wang, Z.; Wu, X.; Tan, Z. Characteristics of (002) Oriented Hydroxyapatite Coatings Deposited by Atmospheric Plasma Spraying. Coatings 2018, 8, 258. [CrossRef]

18. Chrisey, D.B.; Hubler, G.K. Pulsed Laser Deposition of Thin Films, 1st ed.; John Wiley \& Sons: Hoboken, NJ, USA, 1994; pp. 1-649.

19. Eason, R. Pulsed Laser Deposition of Thin Films-Applications-Led Growth of Functional Materials; Wiley-Interscience: Hoboken, NJ, USA, 2006; pp. 1-682.

20. Yang, Y.; Wu, Q.; Wang, M.; Long, J.; Mao, Z.; Chen, X. Hydrothermal Synthesis of Hydroxyapatite with Different Morphologies: Influence of Supersaturation of the Reaction System. Cryst. Growth Des. 2014, 14, 4864-4871. [CrossRef]

21. Zhu, Y.; Xu, L.; Liu, C.; Zhang, C.; Wu, N. Nucleation and growth of hydroxyapatite nanocrystals by hydrothermal method. AIP Adv. 2018, 8, 085221. [CrossRef]

22. Pham, V.H.; Van, H.N.; Tam, P.D.; Ha, H.N.T. A novel $1540 \mathrm{~nm}$ light emission from erbium doped hydroxyapatite/beta-tricalcium phosphate through co-precipitation method. Mater. Lett. 2016, 167, $145-147$. [CrossRef]

23. Ciobanu, C.S.; Popa, C.L.; Predoi, D. Cerium-doped hydroxyapatite nanoparticles synthesized by the co-precipitation method. J. Serb. Chem. Soc. 2016, 81, 433-446. [CrossRef]

24. Papynov, E.K.; Shichalina, O.O.; Modin, E.B.; Yu Mayorov, V.; Portnyagin, A.S.; Kobylyakov, S.P.; Golub, A.V.; Medkov, M.A.; Tananaev, I.G.; Avramenk, V.A. Wollastonite ceramics with bimodal porous structure prepared by Sol-Gel and SPS techniques. RSC Adv. 2016, 6, 34066-34073. [CrossRef]

25. Duta, L.; Mihailescu, N.; Popescu, A.C.; Luculescu, C.R.; Mihailescu, I.N.; Cetin, G.; Gunduz, O.; Oktar, F.N.; Popa, A.C.; Kuncser, A.; et al. Comparative physical, chemical and biological assessment of simple and titanium-doped ovine dentine-derived hydroxyapatite coatings fabricated by pulsed laser deposition. Appl. Surf. Sci. 2017, 413, 129-139. [CrossRef]

26. Oktar, F. Microstructure and mechanical properties of sintered enamel hydroxyapatite. Ceram. Int. 2007, 33, 1309-1314. [CrossRef]

27. Goller, G.; Oktar, F.N.; Agathopoulos, S.; Tulyaganov, D.U.; Ferreira, J.M.F.; Kayali, E.S.; Peker, I. Effect of sintering temperature on mechanical and microstructural properties of bovine hydroxyapatite (BHA). J. Sol-Gel Sci. Techn. 2006, 37, 111-115. [CrossRef]

28. Eisenhart, S. EU Regulation 722. New EU Animal Tissue Regulations in Effect for Some Medical Devices; Emergo: Hong Kong, China, 2013; Available online: https://www.emergobyul.com/blog/2013/09/new-eu-animaltissueregulations-effect-some-medical-devices (accessed on 29 April 2019).

29. ISO 22442-1. Medical Devices Utilizing Animal Tissues and Their Derivatives-Part 1: Application of Risk Management; International Organization for Standardization: Berlin, Germany, 2015.

30. Barakat, N.A.M.; Khil, M.S.; Omran, A.M.; Sheikh, F.A.; Kim, H.Y. Extraction of pure natural hydroxyapatite from the bovine bones bio waste by three different methods. J. Mater. Process. Technol. 2009, 209, 3408-3415. [CrossRef] 
31. Sadat-Shojai, M.; Khorasani, M.T.; Dinpanah-Khoshdargi, E.; Jamshidi, A. Synthesis methods for nanosized hydroxyapatite with diverse structures. Acta Biomater. 2013, 9, 7591-7621. [CrossRef] [PubMed]

32. Elliott, J.C.; Wilson, R.M.; Dowker, S.E.P. Apatite structures. Adv. X-ray Anal. 2002, 45, 172-181.

33. Wopenka, B.; Pasteris, J.D. A mineralogical perspective on the apatite in bone. Mater. Sci. Eng. C 2005, 25, 131-143. [CrossRef]

34. Ben-Nissan, B. Advances in calcium phosphate biomaterials; Part of the Springer Series in Biomaterials Science and Engineering book series; Springer: Berlin, Germany, 2014; Volume 2, p. 547.

35. Mucalo, M. Hydroxyapatite (HAp) for Biomedical Applications; Elsevier: Amsterdam, The Netherlands, 2015; p. 404. [CrossRef]

36. Šupová, M. Substituted hydroxyapatites for biomedical applications: A review. Ceram. Int. 2015, 41, 9203-9231. [CrossRef]

37. Combes, C.; Cazalbou, S.; Rey, C. Apatite biominerals. Minerals 2016, 6, 34. [CrossRef]

38. Fleet, M.E.; Liu, X. Coupled substitution of type A and B carbonate in sodium-bearing apatite. Biomaterials 2007, 28, 916-926. [CrossRef]

39. Astala, R.; Stott, M.J. First principles investigation of mineral component of bone: $\mathrm{CO}_{3}$ substitutions in hydroxyapatite. Chem. Mater. 2005, 17, 4125-4133. [CrossRef]

40. Landi, E.; Tampieri, A.; Mattioli-Belmonte, M.; Celotti, G.; Sandri, M.; Gigante, A.; Fava, P.; Biagini, G. Biomimetic Mg- and Mg, CO3-substituted hydroxyapatites: Synthesis characterization and in vitro behaviour. J. Eur. Ceram. Soc. 2006, 26, 2593-2601. [CrossRef]

41. Tite, T.; Popa, A.-C.; Balescu, L.M.; Bogdan, I.M.; Pasuk, I.; Ferreira, J.M.F.; Stan, G.E. Cationic Substitutions in Hydroxyapatite: Current Status of the Derived Biofunctional Effects and Their In Vitro Interrogation Methods. Materials 2018, 11, 2081. [CrossRef]

42. Verdelis, K.; Lukashova, L.; Wright, J.T.; Mendelsohn, R.; Peterson, M.G.E.; Doty, S.; Boskey, A.L. Maturational changes in dentin mineral properties. Bone 2007, 40, 1399-1407. [CrossRef]

43. Sun, R.-X.; Lv, Y.; Niu, Y.-R.; Zhao, X.-H.; Cao, D.-S.; Tang, J.; Sun, X.-C.; Chen, K.-Z. Physicochemical and biological properties of bovine-derived porous hydroxyapatite/collagen composite and its hydroxyapatite powders. Ceram. Int. 2017, 43, 16792-16798. [CrossRef]

44. Ahmad, N.; Bukhari, S.A.; Akhtar, N.; Haq, I. Serum hormonal, electrolytes and trace element profiles in the rutting and non-rutting one-humped male camel (Camelus dromedarius). Anim. Reprod. Sci. 2007, 101, 172-178.

45. Rahavi, S.S.; Ghaderi, O.; Monshi, A.; Fathi, M.H. A comparative study on physicochemical properties of hydroxyapatite powders derived from natural and synthetic sources. Russ. J. Non-Ferrous Metals 2017, 58, 276-286. [CrossRef]

46. Ofudje, E.A.; Rajendran, A.; Adeogun, A.I.; Idowu, M.A.; Kareem, S.O.; Pattanayak, D.K. Synthesis of organic derived hydroxyapatite scaffold from pig bone waste for tissue engineering applications. Adv. Powder Technol. 2017, 29, 1-8. [CrossRef]

47. Mohd Pu'ad, N.A.S.; Koshy, P.; Abdullah, H.Z.; Idris, M.I.; Lee, T.C. Syntheses of hydroxyapatite from natural sources. Heliyon 2019, 5, e01588. [CrossRef]

48. Labarthe, J.C.; Bonel, G.; Montel, G. Structure and properties of B-type phosphocalcium carbonate apatites. Ann. Chim. 1973, 8, 289-301.

49. Wu, Y.; Glimcher, M.J.; Rey, C.; Ackerman, J.L. A unique protonated phosphate group in bone mineral not present in synthetic calcium phosphates. Identification by phosphorus-31 solid state NMR spectroscopy. J. Mol. Biol. 1994, 244, 423-435. [CrossRef]

50. Winand, L. Etude physico-chimique du phosphate tricalcique hydraté et de l'hydroxyapatite. Ann. Chim. 1961, 6, 951-967.

51. Riggs, B.L.; Hodgson, S.F.; O'Fallon, W.M.; Chao, E.Y.; Wahner, H.W.; Muhs, J.M.; Cedel, S.L.; Melton III, J. Effect of fluoride treatment on the fracture rate in postmenopausal women with osteoporosis. N. Engl. J. Med. 1990, 322, 802-809. [CrossRef]

52. Kay, H.M.; Wilson, M. The in vitro effects of amine fluorides on plaque bacteria. J. Periodontol. 1988, 59, 266-269. [CrossRef]

53. Duta, L.; Oktar, F.N.; Stan, G.E.; Popescu-Pelin, G.; Serban, N.; Luculescu, C.; Mihailescu, I.N. Novel doped hydroxyapatite thin films obtained by pulsed laser deposition. Appl. Surf. Sci. 2013, 265, 41-49. [CrossRef] 
54. Mihailescu, N.; Stan, G.E.; Duta, L.; Chifiriuc, C.M.; Coralia, B.; Sopronyi, M.; Luculescu, C.; Oktar, F.N.; Mihailescu, I.N. Structural, compositional, mechanical characterization and biological assessment of bovine-derived hydroxyapatite coatings reinforced with $\mathrm{MgF}_{2}$ or $\mathrm{MgO}$ for implants functionalization. Mater. Sci. Eng. C 2016, 59, 863-874. [CrossRef]

55. Jayathilakan, K.; Sultana, K.; Radhakrishna, K.; Bawa, A.S. Utilization of byproducts and waste materials from meat, poultry and fish processing industries: a review. J Food Sci Technol. 2012, 49, 278-293. [CrossRef]

56. Kim, S.-H.; Shin, J.-W.; Park, S.-A.; Kim, Y.K.; Park, M.S.; Mok, J.M.; Yang, W.I.; Lee, J.W. Chemical, structural properties, and osteoconductive effectiveness of bone block derived from porcine cancellous bone. J. Biomed. Mater. Res. Part B 2004, 68, 69-74. [CrossRef]

57. Barakat, N.A.M.; Khalil, K.A.; Sheikh, F.A.; Omran, A.M.; Gaihre, B.; Khil, S.M.; Kim, H.Y. Physiochemical characterizations of hydroxyapatite extracted from bovine bones by three different methods: extraction of biologically desirable Hap. Mater. Sci. Eng. C-Mater. 2008, 28, 1381-1387. [CrossRef]

58. Liu, Q.; Huang, S.; Matinlinna, J.P.; Chen, Z.; Pan, H. Insight into Biological Apatite: Physiochemical Properties and Preparation Approaches. Biomed Res. Int. 2013, 2013, 929748. [CrossRef]

59. Seo, D.S.; Kim, Y.G.; Lee, J.K. Sintering and dissolution of bone ash-derived hydroxyapatite. Met. Mater.-Int. 2010, 16, 687-692. [CrossRef]

60. Popescu, A.C.; Florian, P.E.; Stan, G.E.; Popescu-Pelin, G.; Zgura, I.; Enculescu, M.; Oktar, F.N.; Trusca, R.; Sima, L.E.; Roseanu, A.; et al. Physical-chemical characterization and biological assessment of simple and lithium-doped biological-derived hydroxyapatite thin films for a new generation of metallic implants. Appl. Surf. Sci. 2018, 439, 724-735. [CrossRef]

61. Figueiredo, M.; Fernando, A.; Martins, G.; Freitas, J.; Judas, F.; Figueiredo, H. Effect of the calcination temperature on the composition and microstructure of hydroxyapatite derived from human and animal bone. Ceram. Int. 2010, 36, 2383-2393. [CrossRef]

62. Ramesh, S.; Loo, Z.Z.; Tan, C.Y.; Chew, W.J.K.; Ching, Y.C.; Tarlochan, F.; Chandran, H.; Krishnasamy, S.; Bang, L.T.; Sarhan, A.A.D.M. Characterization of biogenic hydroxyapatite derived from animal bones for biomedical applications. Ceram. Int. 2018, 44, 10525-10530. [CrossRef]

63. Akyurt, N.; Yetmez, M.; Karacayli, U.; Gunduz, O.; Agathopoulos, S.; Gökçe, H.; Öveçoğlu, M.L.; Oktar, F.N. A New Natural Biomaterial: Sheep Dentine Derived Hydroxyapatite. Key. Eng. Mater 2012, 493-494, 281-286. [CrossRef]

64. Gheisari, H.; Karamian, E.; Abdellahi, M. A novel hydroxyapatite - hardstonite nanocomposite ceramic. Ceram. Int. 2015, 41, 5967-5975. [CrossRef]

65. Khandan, A.; Abdellahi, M.; Barenji, R.V.; Ozada, N.; Karamian, E. Introducing natural hydroxyapatite-diopside(NHA-Di) nano-bioceramic coating. Ceram. Int. 2015, 41, 12355-12363. [CrossRef]

66. Giraldo-Betancur, A.L.; Espinosa-Arbelaez, D.G.; del Real-López, A.; Millan-Malo, B.M.; Rivera-Muñoz, E.M.; Gutierrez-Cortez, E.; Pineda-Gomez, P.; Jimenez-Sandoval, S.; Rodriguez-García, M.E. Comparison of physicochemical properties of bio and commercial hydroxyapatite. Curr. Appl. Phys. 2013, 13, 1383-1390. [CrossRef]

67. Rincón-López, J.A.; Hermann-Muñoz, J.A.; Giraldo-Betancur, A.L.; De Vizcaya-Ruiz, A.; Alvarado-Orozco, J.M.; Muñoz-Saldaña, J. Synthesis, Characterization and In Vitro Study of Synthetic and Bovine-Derived Hydroxyapatite Ceramics: A Comparison. Materials 2018, 11, 333. [CrossRef] [PubMed]

68. Bianchi, M.; Gambardella, A.; Graziani, G.; Liscio, F.; Maltarello, M.C.; Boi, M.; Berni, M.; Bellucci, D.; Marchiori, G.; Valle, F.; et al. Plasma-assisted deposition of bone apatite-like thin films from natural apatite. Mater. Lett. 2017, 199, 32-36. [CrossRef]

69. Pramanik, S.; Hanif, A.S.M.; Pingguan-Murphy, B.; Osman, N.A.A. Morphological change of heat treated bovine bone: a comparative study. Mater. 2013, 6, 65-75. [CrossRef] [PubMed]

70. Kusrini, E.; Sontang, M. Characterization of x-ray diffraction and electron spin resonance: Effects of sintering time and temperature on bovine hydroxyapatite. Radiat. Phys. Chem. 2012, 81, 118-125. [CrossRef]

71. Bahrololoom, M.E.; Javidi, M.; Javadpour, S.; Ma, J. Characterisation of natural hydroxyapatite extracted from bovine cortical bone ash. J. Ceram. Process. Res. 2009, 10, 129-138.

72. Bano, N.; Jikan, S.S.; Basri, H.; Bakar, S.A.S.A.; Nuhu, A.H. Natural hydroxyapatite extracted from bovine bone. J. Sci. Technol. 2017, 9, 22-28.

73. Ruksudjarit, A.; Pengpat, K.; Rujijanagul, G.; Tunkasiri, T. Synthesis and characterization of nanocrystalline hydroxyapatite from natural bovine bone. Curr. Appl. Phys. 2008, 8, 270-272. [CrossRef] 
74. Nasiri-Tabrizi, B.; Fahami, A.; Ebrahimi-Kahrizsangi, R. A comparative study of hydroxyapatite nanostructures produced under different milling conditions and thermal treatment of bovine bone. J. Ind. Eng. Chem. 2014, 20, 245-258. [CrossRef]

75. Rakmae, S.; Lorprayoon, C.; Ekgasit, S.; Suppakarn, N. Influence of heat-treated bovine bone-derived hydroxyapatite on physical properties and in vitro degradation behavior of poly (lactic acid) composites. Polym. Plast. Technol. 2013, 52, 1043-1053. [CrossRef]

76. Nirmala, R.; Sheikh, F.A.; Kanjwal, M.A.; Lee, J.H.; Park, S.-J.; Navamathavan, R.; Kim, H.Y. Synthesis and characterization of bovine femur bone hydroxyapatite containing silver nanoparticles for the biomedical applications. J. Nanopart. Res. 2011, 13, 1917-1927. [CrossRef]

77. Herliansyah, M.K.; Hamdi, M.; Ide-Ektessabi, A.; Wildan, M.W.; Toque, J.A. The influence of sintering temperature on the properties of compacted bovine hydroxyapatite. Mater. Sci. Eng. C 2009, 29, 1674-1680. [CrossRef]

78. Ayatollahi, M.R.; Yahya, M.Y.; Asgharzadeh Shirazi, H.; Hassan, S.A. Mechanical and tribological properties of hydroxyapatite nanoparticles extracted from natural bovine bone and the bone cement developed by nano-sized bovine hydroxyapatite filler. Ceram. Int. 2015, 41, 10818-10827. [CrossRef]

79. Jaber, H.L.; Hammood, A.S.; Parvin, N. Synthesis and characterization of hydroxyapatite powder from natural Camelus bone. J. Aust. Ceram. Soc. 2018, 54, 1-10. [CrossRef]

80. Duta, L.; Serban, N.; Oktar, F.N.; Mihailescu, I.N. Biological hydroxyapatite thin films synthesized by pulsed laser deposition. Optoelectron. Adv. Mater-Rapid Commun. 2013, 7, 1040-1044.

81. Maidaniuc, A.; Miculescu, F.; Voicu, S.I.; Andronescu, C.; Miculescu, M.; Matei, E.; Mocanu, A.C.; Pencea, I.; Csaki, I.; Machedon-Pisu, T.; et al. Induced wettability and surface-volume correlation of composition for bovine bone derived hydroxyapatite particles. Appl. Surf. Sci. 2018, 438, 158-166. [CrossRef]

82. Ferraro, V.; Carvalho, A.P.; Piccirillo, C.; Santos, M.M.; Castro, P.M.L.; Pintado, M.E. Extraction of high added value biological compounds from sardine, sardine-type fish and mackerel canning residues-A review. Mat. Sci. Eng. C-Mater. 2013, 33, 3111-3120. [CrossRef] [PubMed]

83. Venkatesan, J.; Qian, Z.J.; Ryu, M.; Thomas, N.V.; Kim, S.K. A comparative study of thermal calcination and an alkaline hydrolysis method in the isolation of hydroxyapatite from Thunnus obesus bone. Biomed. Mater. 2011, 6, 12. [CrossRef]

84. Kannan, S.; Rocha, J.H.G.; Agathopoulos, S.; Ferreira, J.M.F. Fluorine-substituted hydroxyapatite scaffolds hydrothermally grown from aragonitic cuttlefish bones. Acta Biomater. 2007, 3, 243-249. [CrossRef] [PubMed]

85. Boutinguiza, M.; Pou, J.; Comesaña, R.; Lusquiños, F.; de Carlos, A.; León, B. Biological hydroxyapatite obtained from fish bones. Mater. Sci. Eng. C-Mater. Biol. Appl. 2012, 32, 478-486. [CrossRef]

86. Huang, Y.C.; Hsiao, P.C.; Chai, H.J. Hydroxyapatite extracted from fish scale: Effects on MG63 osteoblast-like cells. Ceram. Int. 2011, 37, 1825-1831. [CrossRef]

87. Piccirillo, C.; Silva, M.F.; Pullar, R.C.; Braga da Cruz, I.; Jorge, R.; Pintado, M.M.; Castro, P.M. Extraction and characterisation of apatite- and tricalcium phosphate-based materials from cod fish bones. Mat. Sci. Eng. C-Mater. 2013, 33, 103-110. [CrossRef] [PubMed]

88. Senthil, R.; Vedakumari, S.W.; Sastry, T.P. Hydroxyapatite and Demineralized Bone Matrix from Marine Food Waste - A Possible Bone Implant. Am. J. Mat. Synth. Proc. 2018, 3, 1-6. [CrossRef]

89. Hidalgo-Robatto, B.M.; Aguilera-Correa, J.J.; López-Álvarez, M.; Romera, D.; Esteban, J.; Gonzalez, P.; Serra, J. Fluor-carbonated hydroxyapatite coatings by pulsed laser deposition to promote cell viability and antibacterial properties. Surf. Coat. Technol. 2018, 349, 736-744. [CrossRef]

90. Aguiar, H.; Chiussi, S.; López-Álvarez, M.; González, P.; Serra, J. Structural characterization of bioceramics and mineralized tissues based on Raman and XRD techniques. Ceram. Int. 2018, 44, 495-504. [CrossRef]

91. Lopez-Alvarez, M.; Vigo, E.; Rodriguez-Valencia, C.; Outeirino-Iglesias, V.; Gonzalez, P.; Serra, J. In vivo evaluation of shark teeth-derived bioapatites. Clin. Oral Impl. Res. 2016, 28, e91-e100. [CrossRef] [PubMed]

92. Lopez-Alvarez, M.; Pérez-Davila, S.; Rodríguez-Valencia, C.; González, P.; Serra, J. The improved biological response of shark tooth bioapatites in a comparative in vitro study with synthetic and bovine bone grafts. Biomed. Mater. 2016, 11, 035011. [CrossRef]

93. Rivera, E.M.; Araiza, M.; Brostow, W.; Castano, V.M.; Estrada, J.R.D.; Hernandez, R.; Rodrigues, J.R. Synthesis of hydroxyapatite from eggshells. Mater. Lett. 1999, 41, 128-134. [CrossRef] 
94. Elizondo-Villarreal, N.; Martínez-de-la-Cruz, A.; Obregón Guerra, R.; Gómez-Ortega, J.L.; Torres-Martínez, L.M.; Castaño, V.M. Biomaterials from Agricultural Waste: Eggshell-based Hydroxyapatite. Water Air Soil Pollut. 2012, 223, 3643-3646. [CrossRef]

95. Chaudhuri, B.; Mondal, B.; Modak, D.K.; Pramanik, K.; Chaudhuri, B.K. Preparation and characterization of nanocrystalline hydroxyapatite from eggshell and K2HPO4 solution. Mater. Lett. 2013, 97, 148-150. [CrossRef]

96. Tamasan, M.; Ozyegin, L.S.; Oktar, F.N.; Simon, V. Characterization of calcium phosphate powders originating from Phyllacanthus imperialis and Trochidae Infundibulum concavus marine shells. Mat. Sci. Eng. C-Mater 2013, 33, 2569-2577. [CrossRef]

97. Gunduz, O.; Sahin, Y.M.; Agathopoulos, S.; Ben-Nissan, B.; Oktar, F.N. A New Method for Fabrication of Nanohydroxyapatite and TCP from the Sea Snail Cerithium vulgatum. J. Nanomater. 2014, 2014, 382861. [CrossRef]

98. Li, S.; Wang, J.; Jing, X.; Liu, Q.; Saba, J.; Mann, T.; Zhang, M.; Wei, H.; Chen, R.; Liu, L. Conversion of calcined eggshells into flower-like hydroxyapatite agglomerates by solvothermal method using Hydrogen peroxide/N,N-dimethylformamide mixed solvents. J. Am. Ceram. Soc. 2012, 95, 3377-3379. [CrossRef]

99. Ho, W.-F.; Hsu, H.-C.; Hsu, S.-K.; Hung, C.-W.; Wu, S.-C. Calcium phosphate bioceramics synthesized from eggshell powders through a solid state reaction. Ceram. Int. 2013, 39, 6467-6473. [CrossRef]

100. Surmenev, R.A. A review of plasma-assisted methods for calcium phosphate-based coatings fabrication. Surf. Coat. Technol. 2012, 206, 2035-2056. [CrossRef]

101. Surmenev, R.A.; Surmeneva, M.A.; Ivanova, A.A. Significance of calcium phosphate coatings for the enhancement of new bone osteogenesis-A review. Acta Biomater. 2014, 10, 557-579. [CrossRef]

102. Graziani, G.; Boi, M.; Bianchi, M. A Review on Ionic Substitutions in Hydroxyapatite Thin Films: Towards Complete Biomimetism. Coatings 2018, 8, 269. [CrossRef]

103. Schneider, C.W.; Lippert, T. Laser Ablation and Thin Film Deposition. In Laser Processing of Materials; Schaaf, P., Ed.; Springer Series in Materials Science; Springer: Berlin/Heidelberg, Germany, 2010; Volume 139, pp. 89-112.

104. Caricato, A.P.; Martino, M.; Romano, F.; Mirchin, N.; Peled, A. Pulsed laser photodeposition of a-Se nanofilms by ArF laser. Appl. Surf. Sci. 2007, 253, 6517-6521. [CrossRef]

105. Hashimoto, Y.; Ueda, M.; Kohiga, Y.; Imura, K.; Hontsu, S. Application of fluoridated hydroxyapatite thin film coatings using KrF pulsed laser deposition. Dent Mater J. 2018, 37, 408-413. [CrossRef] [PubMed]

106. Zaki, A.M.; Blythe, H.J.; Heald, S.M.; Fox, A.M.; Gehring, G.A. Growth of high quality yttrium iron garnet films using standard pulsed laser deposition technique. J. Magn. Magn. Mater. 2018, 453, 254-257. [CrossRef]

107. Novotný, M.; Vondráček, M.; Marešová, E.; Fitl, P.; Bulíř, J.; Pokornýa, P.; Havlová, Š.; Abdellaoui, N.; Pereira, A.; Hubík, P.; et al. Optical and structural properties of ZnO:Eu thin films grown by pulsed laser deposition. Appl. Surf. Sci. 2019, 476, 271-275. [CrossRef]

108. Gyorgy, E.; Ristoscu, C.; Mihailescu, I.N. Role of laser pulse duration and gas pressure in deposition of AlN thin films. J. Appl. Phys. 2001, 90, 456. [CrossRef]

109. Boyd, I.W. Thin film growth by pulsed laser deposition. Ceram. Int. 1996, 22, 429-434. [CrossRef]

110. Popescu, A.C.; Duta, L.; Dorcioman, G.; Mihailescu, I.N.; Stan, G.E.; Pasuk, I.; Zgura, I.; Beica, T.; Enculescu, I.; Ianculescu, A.; et al. Radical modification of the wetting behavior of textiles coated with $\mathrm{ZnO}$ thin films and nanoparticles when changing the ambient pressure in the pulsed laser deposition process. J. Appl. Phys. 2011, 110, 064321. [CrossRef]

111. Murray, M.; Jose, G.; Richards, B.; Jha, A. Femtosecond pulsed laser deposition of silicon thin films. Nanoscale Res. Lett. 2013, 8, 272. [CrossRef] [PubMed]

112. Fehse, M.; Trócoli, R.; Hernández, E.; Ventosa, E.; Sepúlveda, A.; Morata, A.; Tarancón, A. An innovative multi-layer pulsed laser deposition approach for $\mathrm{LiMn}_{2} \mathrm{O}_{4}$ thin film cathodes. Thin Solid Films 2018, 648, 108-112. [CrossRef]

113. Stock, F.; Diebold, L.; Antoni, F.; Chowde Gowda, C.; Muller, D.; Haffner, T.; Pfeiffer, P.; Roques, S.; Mathiot, D. Silicon and silicon-germanium nanoparticles obtained by Pulsed Laser Deposition. Appl. Surf. Sci. 2019, 466, 375-380. [CrossRef]

114. Craciun, D.; Socol, G.; Stefan, N.; Miroiu, M.; Mihailescu, I.N.; Galca, A.C.; Craciun, V. Structural investigations of ITO-ZnO films grown by the combinatorial pulsed laser deposition technique. Appl. Surf. Sci. 2009, 255, 5288-5291. [CrossRef] 
115. Rasoga, O.; Sima, L.; Chiritoiu, M.; Popescu-Pelin, G.; Fufa, O.; Grumezescu, V.; Socol, M.; Stanculescu, A.; Zgura, I.; Socol, G. Biocomposite coatings based on Poly(3-hydroxybutyrate-co-3-hydroxyvalerate)/calcium phosphates obtained by MAPLE for bone tissue engineering. Appl. Surf. Sci. 2017, 417, 204-212. [CrossRef]

116. Mihailescu, I.N.; Gyorgy, E. Pulsed Laser Deposition: An overview. In International Trends in Optics and Photonics; Asakura, T., Ed.; Part of the Springer Series in Optical Sciences book series; Springer: Heidelberg, Germany, 1999; Volume 74, pp. 201-214. [CrossRef]

117. Ozyegin, L.S.; Oktar, F.N.; Goller, G.; Kayali, S.; Yazici, T. Plasma-sprayed bovine hydroxyapatite coatings. Mater. Lett. 2004, 58, 2605-2609. [CrossRef]

118. Aguzzi, A. Prion diseases of humans and farm animals: Epidemiology, genetics, and pathogenesis. J. Neurochem. 2006, 97, 1726-1739. [CrossRef]

119. Paital, S.R.; Dahotre, N.B. Calcium phosphate coatings for bio-implant applications: Materials, performance factors, and methodologies. Mater. Sci. Eng. R-Rep. 2009, 66, 1-70. [CrossRef]

120. Park, J.-W.; Park, K.-B.; Suh, J.-Y. Effects of calcium ion incorporation on bone healing of Ti6Al4V alloy implants in rabbit tibiae. Biomaterials 2007, 28, 3306-3313. [CrossRef]

121. Bai, Y.; Park, I.S.; Lee, S.J.; Bae, T.S.; Duncan, W.; Swain, M.; Lee, M.H. One-step approach for hydroxyapatite-incorporated $\mathrm{TiO}_{2}$ coating on titanium via a combined technique of micro-arc oxidation and electrophoretic deposition. Appl. Surf. Sci. 2011, 257, 7010-7018. [CrossRef]

122. Liu, L.-S.; Thompson, A.Y.; Heidaran, M.A.; Poser, J.W.; Spiro, R.C. An osteoconductive collagen/hyaluronate matrix for bone regeneration. Biomaterials 1999, 20, 1097-1108. [CrossRef]

123. Ratner, B.D.; Hoffman, A.S.; Schoen, F.J.; Lemons, J.E. Biomaterials Science7-An Introduction to Materials in Medicine, 2nd ed.; Elsevier Academic Press: San Diego, CA, USA, 2004; p. 864.

124. Mandracci, P.; Mussano, F.; Rivolo, P.; Carossa, S. Surface Treatments and Functional Coatings for Biocompatibility Improvement and Bacterial Adhesion Reduction in Dental Implantology. Coatings 2016, 6, 7. [CrossRef]

125. Traini, T.; Murmura, G.; Sinjari, B.; Perfetti, G.; Scarano, A.; D'Arcangelo, C.; Caputi, S. The Surface Anodization of Titanium Dental Implants Improves Blood Clot Formation Followed by Osseointegration. Coatings 2018, 8, 252. [CrossRef]

126. Han, A.; Tsoi, J.K.-H.; Matinlinna, J.P.; Chen, Z. Influence of Grit-Blasting and Hydrofluoric Acid Etching Treatment on Surface Characteristics and Biofilm Formation on Zirconia. Coatings 2017, 7, 130. [CrossRef]

127. Zhou, G.; Bi, Y.; Ma, Y.; Wang, L.; Wang, X.; Yu, Y.; Mutzk, A. Large current ion beam polishing and characterization of mechanically finished titanium alloy (Ti6Al4V) surface. Appl. Surf. Sci. 2019, 476, 905-913. [CrossRef]

128. Chen, R.; Li, S.; Wang, Z.; Lu, X. Mechanical model of single abrasive during chemical mechanical polishing: molecular dynamics simulation. Tribol. Int. 2019, 133, 40-46. [CrossRef]

129. Singh, H.; Sharma, V.S.; Singh, S.; Dogra, M. Nanofluids assisted environmental friendly lubricating strategies for the surface grinding of titanium alloy: Ti6Al4V-ELI. J. Manuf. Process. 2019, 39, 241-249. [CrossRef]

130. Eliaz, N.; Ritman-Hertz, O.; Aronov, D.; Weinberg, E.; Shenhar, Y.; Rosenman, G.; Weinreb, M.; Ron, E. The effect of surface treatments on the adhesion of electrochemically deposited hydroxyapatite coating to titanium and on its interaction with cells and bacteria. J. Mater. Sci. Mater. Med. 2011, 22, 1741-1752. [CrossRef]

131. Liu, C.-F.; Li, S.-J.; Hou, W.-T.; Hao, Y.-L.; Huang, H.-H. Enhancing Corrosion Resistance and Biocompatibility of Interconnected Porous $\beta$-type Ti-24Nb-4Zr-8Sn Alloy Scaffold through Alkaline Treatment and Type I Collagen Immobilization. Appl. Surf. Sci. 2019, 476, 325-334. [CrossRef]

132. Peng, F.; Shaw, M.T.; Olson, J.R.; Wei, M. Influence of surface treatment and biomimetic hydroxyapatite coating on the mechanical properties of hydroxyapatite/poly(L-lactic acid) fibers. J. Biomater. Appl. 2013, 27, 641-649. [CrossRef] [PubMed]

133. Dorozhkin, S.V. Calcium orthophosphate deposits: Preparation, properties and biomedical applications. Mater. Sci. Eng. C 2015, 55, 272-326. [CrossRef]

134. Koh, A.T.T.; Foong, Y.M.; Chua, D.H.C. Cooling rate and energy dependence of pulsed laser fabricated graphene on nickel at reduced temperature. Appl. Phys. Lett. 2010, 97, 114102. [CrossRef]

135. Yang, Z.; Hao, J. Progress in pulsed laser deposited two-dimensional layered materials for device applications. J. Mater. Chem. C 2016, 4, 8859-8878. [CrossRef] 
136. Christen, H.M.; Eres, G. Recent advances in pulsed-laser deposition of complex oxides. J. Phys. Condens. Matter. 2008, 20, 264005. [CrossRef]

137. Saju, K.K.; Reshmi, R.; Jayadas, N.H.; James, J.; Jayaraj, M.K. Polycrystalline coating of hydroxyapatite on TiAl6V4 implant material grown at lower substrate temperatures by hydrothermal annealing after pulsed laser deposition. Proc. Inst. Mech. Eng. Part H-J. Eng. Med. 2009, 223, 1049-1057. [CrossRef]

138. Lynn, A.K.; DuQuesnay, D.L. Hydroxyapatite-coated Ti-6Al-4V Part 2: the effects of post-deposition heat treatment at low temperatures. Biomaterials 2002, 23, 1947-1953. [CrossRef]

139. Lu, Y.P.; Chen, Y.M.; Li, S.T.; Wang, J.H. Surface nanocrystallization of hydroxyapatite coating. Acta Biomater. 2008, 4, 1865-1872. [CrossRef]

140. Drevet, R.; Fauré, J.; Benhayoune, H. Thermal treatment optimization of electrodeposited hydroxyapatite coatings on Ti6Al4V substrate. Adv. Eng. Mater. 2012, 14, 377-382. [CrossRef]

141. Azis, S.A.A.; Kennedy, J.; Cao, P. Effect of annealing on microstructure of hydroxyapatite coatings and their behaviours in simulated body fluid. Adv. Mater. Res. 2014, 922, 657-662. [CrossRef]

142. Yang, Y.; Kim, K.H.; Agrawal, C.M.; Ong, J.L. Influence of post-deposition heating time and the presence of water vapor on sputter-coated calcium phosphate crystallinity. J. Dent. Res. 2003, 82, 833-837. [CrossRef]

143. Yang, Y.Z.; Kim, K.H.; Agrawal, C.M.; Ong, J.L. Effect of post-deposition heating temperature and the presence of water vapor during heat treatment on crystallinity of calcium phosphate coatings. Biomaterials 2003, 24, 5131-5137. [CrossRef]

144. Dinda, G.P.; Shin, J.; Mazumder, J. Pulsed laser deposition of hydroxyapatite thin films on Ti-6Al-4V: Effect of heat treatment on structure and properties. Acta Biomaterialia 2009, 5, 1821-1830. [CrossRef]

145. Zhou, J.; Zhang, X.; Chen, J.; Zeng, S.; De Groot, K. High temperature characteristics of synthetic hydroxyapatite. J. Mater. Sci.: Mater. In Med. 1993, 4, 83-85. [CrossRef]

146. Stan, G.E.; Pasuk, I.; Husanu, M.A.; Enculescu, I.; Pina, S.; Lemos, A.F.; Tulyaganov, D.U.; Mabrouk, K.E.L.; Ferreira, J.M.F. Highly adherent bioactive glass thin films synthesized by magnetron sputtering at low temperature. J. Mater. Sci.-Mater. Med. 2011, 22, 2693-2710. [CrossRef]

147. DFD®INSTRUMENTS. Available online: www.dfdinstruments.com (accessed on 29 April 2019).

148. Bao, Q.; Chen, C.; Wang, D.; Ji, Q.; Lei, T. Pulsed laser deposition and its current research status in preparing hydroxyapatite thin films. Appl. Surf. Sci. 2005, 252, 1538-1544. [CrossRef]

149. Mohseni, E.; Zalnezhad, E.; Bushroa, A.R. Comparative investigation on the adhesion of hydroxyapatite coating on Ti-6Al-4V implant: a review paper. Int. J. Adhes. Adhes. 2014, 48, 238-257. [CrossRef]

150. Stan, G.E. Adherent functional graded hydroxylapatite coatings produced by sputtering deposition techniques. J. Optolelectron. Adv. Mater. 2009, 11, 1132-1138.

151. Stan, G.E.; Morosanu, C.O.; Marcov, D.A.; Pasuk, I.; Miculescu, F.; Reumont, G. Effect of annealing upon the structure and adhesion properties of sputtered bio-glass/titanium coatings. Appl. Surf. Sci. 2009, 255, 9132-9138. [CrossRef]

152. Stan, G.E.; Popa, A.C.; Galca, A.C.; Aldica, G.; Ferreira, J.M.F. Strong bonding between sputtered bioglass-ceramic films and Ti-substrate implants induced by atomic inter-diffusion post-deposition heat-treatments. Appl. Surf. Sci. 2013, 280, 530-538. [CrossRef]

153. ISO 13779-2. Implants for Surgery-Hydroxyapatite-Part 2: Coatings of Hydroxyapatite; ISO: Geneva, Switzerland, 2008.

154. ISO 10993-5: 2009. Biological Evaluation of Medical Devices-Part 5: Tests for in vitro cytotoxicity; ISO: Geneva, Switzerland, 2009.

155. Cleare, A.; Pariante, C.M.; Young, A.H.; Anderson, I.M.; Christmas, D.; Cowen, P.J.; Dickens, C.; Ferrier, I.N.; Geddes, J.; Gilbody, S.; et al. Evidence-based guidelines for treating depressive disorders with antidepressants: A revision of the 2008 British Association for Psychopharmacology guidelines. J. Psychopharmacol. 2015, 29, 459-525. [CrossRef]

156. Cohen, O.; Rais, T.; Lepkifker, E.; Vered, I. Lithium carbonate therapy is not a risk factor for osteoporosis. Horm. Metab. Res. 1998, 30, 594-597. [CrossRef]

157. Nordenstrom, J.; Elvius, M.; Bagedahl-Strindlund, M.; Zhao, B.; Torring, O. Biochemical hyperparathyroidism and bone-mineral status in patients treated long-term with lithium. Metabolism 1994, 43, 1563-1567. [CrossRef]

158. Satija, N.K.; Sharma, D.; Afrin, F.; Tripathi, R.P.; Gangenahalli, G. High throughput transcriptome profiling of lithium stimulated human mesenchymal stem cells reveals priming towards osteoblastic lineage. PLoS ONE 2013, 8, e55769. [CrossRef] [PubMed] 
159. Yang, M.L.; Li, J.J.; So, K.F.; Chen, J.Y.H.; Cheng, W.S.; Wu, J.; Wang, Z.M.; Gao, F.; Young, W. Efficacy and safety of lithium carbonate treatment of chronic spinal cord injuries: A double-blind, randomized, placebo-controlled clinical trial. Spinal Cord 2012, 50, 141-146. [CrossRef]

160. Gitlin, M. Lithium side effects and toxicity: Prevalence and management strategies. Int. J. Bipolar Disord. 2016, 4, 27. [CrossRef] [PubMed]

161. Ott, M.; Stegmayr, B.; Salander, R.E.; Werneke, U. Lithium intoxication: Incidence, clinical course and renal function-A population-based retrospective cohort study. J. Psychopharmacol. 2016, 30, 1008-1019. [CrossRef]

162. Rybakowski, J.K. Challenging the negative perception of lithium and optimizing its long-term administration. Front. Mol. Neurosci. 2018, 11, 349. [CrossRef]

163. Post, R.M. The new news about lithium: An underutilized treatment in the United States. Neuropsychopharmacology 2018, 43, 1174-1179. [CrossRef]

164. Kandori, K.; Kuroda, T.; Wakamura, M. Protein adsorption behaviors onto photocatalytic Ti(IV)-doped calcium hydroxyapatite particles. Colloid Surf. B Biointerfaces 2011, 87, 472-479. [CrossRef]

165. Wei, W.; Zhang, X.; Cui, J.; Wei, Z. Interaction between low molecular weight organic acids and hydroxyapatite with different degrees of crystallinity. Colloid Surf. A Physicochem. Eng. Aspect 2011, 392, 67-75. [CrossRef]

166. Pesakova, V.; Kubies, D.; Hulejova, H.; Himmlova, L. The influence of implant surface properties on cell adhesion and proliferation. J. Mater. Sci.-Mater. Med. 2007, 18, 465-473. [CrossRef]

167. Ng, C.H.; Rao, N.; Law, W.C.; Xu, G.; Cheung, T.L.; Cheng, F.T.; Wang, X.; Man, H.C. Enhancing the cell proliferation performance of NiTi substrate by laser diffusion nitriding. Surf. Coat. Technol. 2017, 309, 59-66. [CrossRef]

168. Webb, K.; Hlady, V.; Tresco, P.A. Relative importance of surface wettability and charged functional groups on NIH 3 T3 fibroblast attachment, spreading, and cytoskeletal organization. J. Biomed. Mater. Res. 1998, 41, 422-430. [CrossRef]

169. Dos Santos, E.A.; Farina, M.; Soares, G.A.; Anselme, K. Surface energy of hydroxyapatite and beta-tricalcium phosphate ceramics driving serum protein adsorption and osteoblast adhesion. J. Mater. Sci.: Mater. Med. 2008, 19, 2307-2316. [CrossRef]

170. Redey, S.A.; Razzouk, S.; Rey, C.; Bernache-Assollant, D.; Leroy, G.; Nardin, M.; Cournot, G. Osteoclast adhesion and activity on synthetic hydroxyapatite, carbonated hydroxyapatite, and natural calcium carbonate: Relationship to surface energies. J. Biomed. Mater. Res. 1999, 45, 140-147. [CrossRef]

171. Zhao, G.; Schwartz, Z.; Wieland, M.; Rupp, F.; Geis-Gerstorfer, J.; Cochran, D.L.; Boyan, B.D. High surface energy enhances cell response to titanium substrate microstructure. J. Biomed. Mater. Res. 2005, 74, 49-58. [CrossRef]

172. Vidic, J.; Stankic, S.; Haque, F.; Ciric, D.; Goffic, R.L.; Vidy, A.; Jupille, J.; Delmas, B. Selective antibacterial effects of mixed ZnMgO nanoparticles. J. Nanoparticle Res. 2013, 15, 1595. [CrossRef] [PubMed]

173. Li, Y.; Liu, G.; Zhai, Z.; Liu, L.; Li, H.; Yang, K.; Tan, L.; Wan, P.; Liu, X.; Ouyang, Z.; et al. Antibacterial Properties of Magnesium In Vitro and in an In Vivo Model of Implant-Associated Methicillin-Resistant Staphylococcus aureus Infection. Antimicrob Agents Chemother. 2014, 58, 7586-7591. [CrossRef]

174. Sawai, J.; Kojima, H.; Igarashi, H.; Hashimoto, A.; Shoji, S.; Sawaki, T.; Hakoda, A.; Kawada, E.; Kokugan, T.; Shimizu, M. Antibacterial characteristics of magnesium oxide powder. World J. Microbiol. Biotechnol. 2000, 16, 187. [CrossRef]

175. Gayathri, B.; Muthukumarasamy, N.; Velauthapillai, D.; Santhosh, S.B.; asokan, V. Magnesium incorporated hydroxyapatite nanoparticles: Preparation, characterization, antibacterial and larvicidal activity. Arab. J. Chem. 2018, 11, 645-654. [CrossRef]

176. Applerot, G.; Lipovsky, A.; Dror, R.; Perkas, N.; Nitzan, Y.; Lubart, R.; Gedanken, A. Enhanced Antibacterial Activity of Nanocrystalline ZnO Due to Increased ROS-Mediated Cell Injury. Adv. Funct. Matter. 2009, 19, 842-852. [CrossRef]

177. Schwalfenberg, G.K.; Genuis, S.J. The Importance of Magnesium in Clinical Healthcare. Scientifica (Cairo) 2017, 2017, 4179326. [CrossRef] [PubMed]

178. Barrere, F.; van der Valk, C.M.; Meijer, G.; Dalmeijer, R.A.; Groot, K.; Layrolle, P. Osteointegration of biomimetic apatite coating applied onto dense and porous metal implants in femurs of goats. J. Biomed. Mater. Res. B Appl. Biomater. 2003, 67, 655-665. [CrossRef] 
179. Surmenev, R.A.; Surmeneva, M.A. A critical review of decades of research on calcium phosphate-based coatings: How far are we from their widespread clinical application? Curr. Opin. Biomed. Eng. 2019, 10, 35-44. [CrossRef]

180. Chen, L.; Komasa, S.; Hashimoto, Y.; Hontsu, S.; Okazaki, J. In Vitro and In Vivo Osteogenic Activity of Titanium Implants Coated by Pulsed Laser Deposition with a Thin Film of Fluoridated Hydroxyapatite. Int. J. Mol. Sci. 2018, 19, 1127. [CrossRef]

181. Mróz, W.; Budner, B.; Syroka, R.; Niedzielski, K.; Golański, G.; Slósarczyk, A.; Schwarze, D.; Douglas, T.E. In vivo implantation of porous titanium alloy implants coated with magnesium-doped octacalcium phosphate and hydroxyapatite thin films using pulsed laser deposition. J. Biomed. Mater. Res. Part B 2015, 103, 151-158. [CrossRef]

182. Peraire, C.; Arias, J.L.; Bernal, D.; Pou, J.; Leon, B.; Arano, A.; Roth, W. Biological stability and osteoconductivity in rabbit tibia of pulsed laser deposited hydroxylapatite coatings. J. Biomed. Mater. Res. Part A 2006, 77A, 370-379. [CrossRef]

183. Mihailescu, I.N.; Lamolle, S.; Socol, G.; Miroiu, F.; Roenold, H.J.; Bigi, A.; Mayer, I.; Cuisinier, F.; Lyngstadaas, S.P. In vivo tensile tests of biomimetic titanium implants pulsed laser coated with nanostructured Calcium Phosphate thin films. Optoelectron. Adv. Mater.-Rapid Commun. 2008, 2, 337-341.

184. Dostalova, T.; Himmlova, L.; Jelinek, M.; Grivas, C. Osseointegration of loaded dental implant with KrF laser hydroxylapatite films on Ti6Al4V alloy by minipigs. J. Biomed. Opt. 2001, 6, 239-243. [CrossRef]

(C) 2019 by the authors. Licensee MDPI, Basel, Switzerland. This article is an open access article distributed under the terms and conditions of the Creative Commons Attribution (CC BY) license (http://creativecommons.org/licenses/by/4.0/). 